Research Article

\title{
Experimental Investigation on the Vibration Reduction Characteristics of an Optimized Heavy-Haul Railway Low-Vibration Track
}

\author{
Zhiping Zeng $\mathbb{D}^{1,2}$ Jundong Wang ${ }^{1 D},{ }^{1}$ Huatuo Yin, ${ }^{3}$ Shiwen Shen, ${ }^{1}$ \\ Abdulmumin Ahmed Shuaibu, ${ }^{2}$ and Weidong Wang ${ }^{1,2}$ \\ ${ }^{1}$ School of Civil Engineering, Central South University, Changsha, Hunan 410075, China \\ ${ }^{2}$ Key Laboratory of Engineering Structure of Heavy Haul Railway (Central South University), \\ Ministry of Education, Changsha, Hunan 410075, China \\ ${ }^{3}$ Guangzhou Metro Design \& Research Institute Co., Ltd., Guangzhou, Guangdong 510000, China
}

Correspondence should be addressed to Jundong Wang; 174812173@csu.edu.cn

Received 18 December 2018; Accepted 16 January 2019; Published 25 February 2019

Academic Editor: Marc Thomas

Copyright (c) 2019 Zhiping Zeng et al. This is an open access article distributed under the Creative Commons Attribution License, which permits unrestricted use, distribution, and reproduction in any medium, provided the original work is properly cited.

\begin{abstract}
Heavy-haul railway has been developed rapidly in many countries in the world due to its great social and economic benefits. One of the key technologies for heavy-haul railway is the reduction of vibration on the track structures and its surrounding due to impact load induced by the train in service. The vibration behaviors of two kinds of low-vibration track (LVT) systems for heavyhaul railway are investigated in this paper. Firstly, two indoor full-scale low-vibration track models (new LVT and traditional LVT), which include rail, fastener, bearing block, rubber boot, track slab, and foundation base, were constructed according to design drawings. Secondly, the vibration responses of the different track components under the impact excitation of a dropping wheelset were measured. Thirdly, the time-domain characteristics of each track component of the two LVTs were compared by the acquired vibration time-history curves. Finally, the frequency-domain distribution was analyzed, and the vibration reduction performance was evaluated by the comprehensive time-frequency analysis results. The results show the new LVT has lower vibration acceleration, shorter duration of vibration period, lower vibration frequency of track components, and most importantly an obvious vibration reduction effect on the ground. The research results are useful to further optimize the design of LVT to reduce the vibration under train impact load.
\end{abstract}

\section{Introduction}

Heavy-haul railways have great freight conveying capacity and have created great social and economic benefits [1-3]. To sustain these benefits, there is need to design improved track structure systems that will focus primarily on accommodating increased axle loads, faster operating speeds, and reduced track maintenance cycles [4-6]. Therefore, reducing the wheel-rail impact load is crucial for the track structure design. It is widely accepted that these wheels cause large dynamic forces and that there is a limit to the magnitude of force which may be applied to the track $[7,8]$.
In recent years, many researchers have explored on exploration influence of dynamic impact on the track structures. Newton and Clark [8] focused primarily on the stresses in the rail due to a wheel flat. They estimated the forces of interaction between the wheel and rail using a linear track model and compared these forces with measured data for a rail irregularity. Wu and Thompson [9] studied wheel-track impact using a nonlinear track FEM at different train speeds on three types of rail pad. Dukkipati and Dong [10] established an FE model of the wheel-rail system and studied the relationship between the stiffness of the pad under slab and the wheel-rail impact force as well as the 
stress and strain on the rail. Bian et al. [5] explored the relationships between the impact force and the wheel flat size.

Other scholars have done a lot of study on how to reduce the vibration of the track structures. Werning et al. [11] optimized the shape of wheels to realize the low-noise potential in freight railway. Liu et al. [12] developed a compound track-absorber model to study the effectiveness of the rail absorber and the influence of its bending modes and concluded that rail vibration energy could be substantially reduced in the corresponding frequency region. Costa et al. [13] discussed the effects of the ballast mat stiffness and location in depth on the reduction of highfrequency vibrations transmitted to the ground. Hussein and Hunt [14] considered three different arrangements of supports for floating-slab tracks to control vibration from underground railways. Auersch [15] investigated the vibration characteristics of the floating-slab track and found that it has a dominating plate-mat resonance and a strong high-frequency reduction. Wang and Zeng [16] used rubbermodified asphalt concrete as a material for high-speed railway track slab underlayment to minimize the vibrations. The abovementioned literature provides a research basis for wheel-rail impact and a reference for the optimization and design of track structure to improve the influence of wheel-rail impact.

During heavy-haul railway operations, there are some unfavorable phenomena in the ballasted track due to dynamic impact. For example, the ballast is broken or even powdered and the sleeper could fail [17-20]. Thus, it is necessary to perform frequent maintenance to keep the track functional at all times. However, the ballasted track maintenance and repair is usually very difficult in long tunnel because of the small working space that inhibits the size of large machine and lack of ventilation. Compared with the ballasted track, the ballastless track has the advantages of lower deformation and less maintenance and has been highlighted on the high-speed railway [21,22]. Due to these advantages, the ballastless track has gained popularity in heavy-haul railway in China [23]. Because the low-vibration track (LVT) structure can effectively reduce the impact loads of heavy-haul railways due to wheel-rail and the vibration level of the tunnel foundation, thus, it was applied in the tunnel of the Inner Mongolia-Huazhong Coal Transportation Heavy-Haul Railway in China. But the bearing block system of the LVT is susceptible to excessive deformation, which results in wheel-rail impact and uneven forces distribution in elastic members, poor maintenance of the geometrical position of the line, and increased construction and maintenance costs.

In order to further improve the vibration damping performance of the LVT and reduce the vibration level of the track components caused by the wheel-rail impact as well as justify the need to reduce vibration of the traditional LVT (TLVT) (T-LVT), this paper proposes a new LVT (N-LVT). This study aims at evaluating the vibration characteristics of the N-LVT and T-LVT systems under impact excitation. Two fullscale indoor models were established, and the vertical vibration was obtained using the wheelset dropping impact test method. In addition, the dynamic performance of the track structure was obtained and compared in the time and frequency domains [24-26]. The first section of the paper gives an overview of the full-scale model, the second section introduces the test method adopted in this paper, while the third, fourth, and fifth sections analyze the transmission attenuation of the vertical impact acceleration along the longitudinal, vertical, and lateral directions of the track, respectively.

\section{Overview of the Full-Scale Model}

This paper presents the vibration characteristics under impact excitations of the two LVTs. The N-LVT was designed based on the T-LVT. For the purpose to improve vibration characteristics of the T-LVT, the N-LVT is optimized for the size of the bearing block, the rubber pad under the bearing block, and the rubber boot. The short side slope of the bearing block is adjusted from $1: 17$ to $1: 4.85$; the rubber boot and the rubber pad under the bearing block in the N-LVT are integrated. The images of the N-LVT and T-LVT bearing blocks and rubber boots are shown in Figure 1.

The overall structural dimensions of the LVT have adopted the existing design size. The construction procedure of the models was completely the same as the construction of the real LVT structure in order to ensure the experiment can reflect real operating condition exactly. The cross section of the two LVTs in a straight section in tunnel is shown in Figures 2(a) and 2(b).

The LVTs were constructed in the Key Laboratory of Engineering Structure of Heavy-Haul Railway in Central South University of China. The dimensions of the track slab and the foundation base are $6580 \mathrm{~mm} \times 2800 \mathrm{~mm} \times 400 \mathrm{~mm}$ and $6800 \mathrm{~mm} \times 3000 \mathrm{~mm} \times 200 \mathrm{~mm}$, respectively. Each LVT includes 11 pairs of bearing blocks, and the fastener spacing is $600 \mathrm{~mm}$. The design and the physical maps of the full-scale model are shown in Figures 3(a), 3(b), 4(a), and 4(b), respectively.

\section{Overview of Experiment Methods}

3.1. Test Method. The wheelset dropping test method of the Japan National Railways Institute of Technology was used to compare the vibration characteristics of the track structure $[27,28]$. This method measures the dynamic response of the track components such as the rail, the bearing block, the track slab, the foundation base, and the ground, when the wheelset impacts the rail with free dropping at the heights of $20 \mathrm{~mm}$ [29]. During the experiment, a heavy-haul train wheelset was used to analyze and compare the impact vibration response characteristics of the two track structures. The actual wheelset was placed directly above the fastener No. 6 in the middle of the full-scale model, as shown in Figure 5.

By testing the acceleration amplitude of each track structural component from the rail to the ground, the vibration transmission and the impact attenuation performance between the adjacent track structures can be analyzed. The vibration parameters of the track structure such as the elastic 


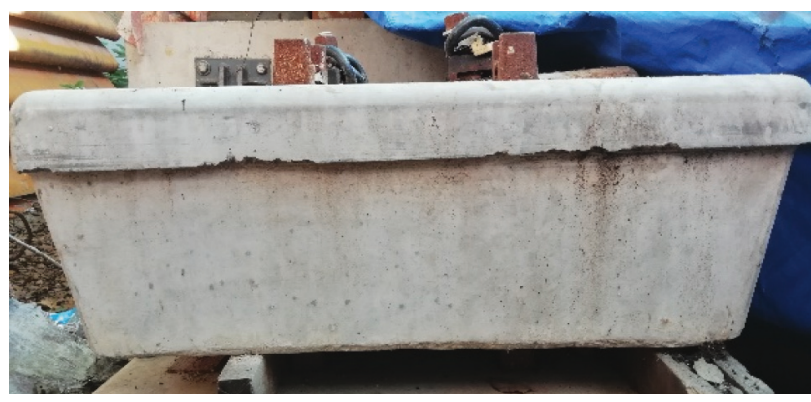

(a)

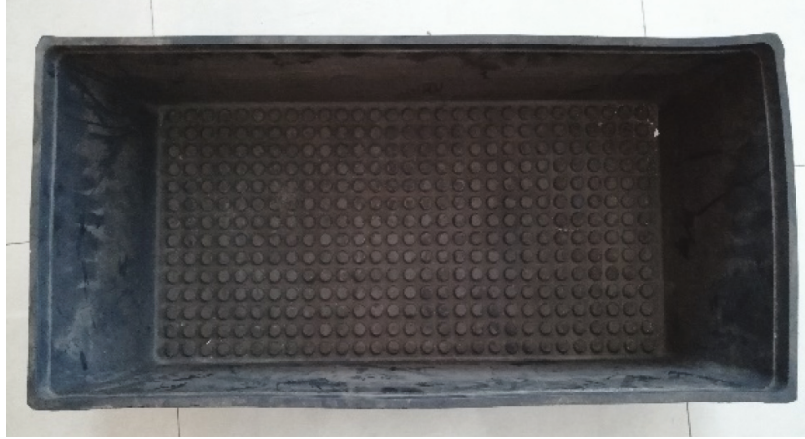

(c)

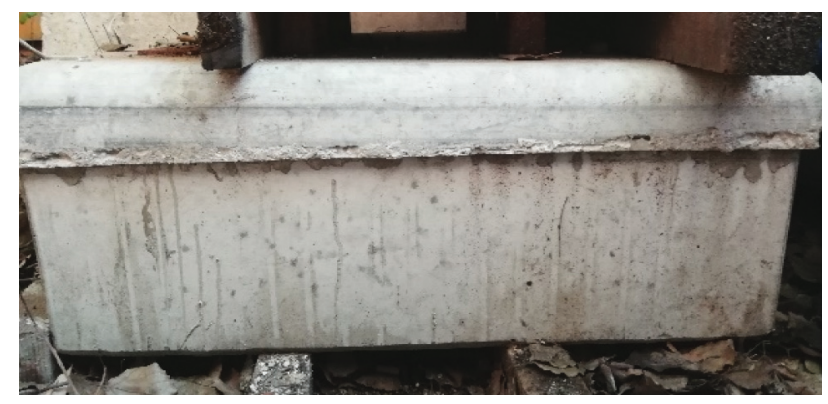

(b)

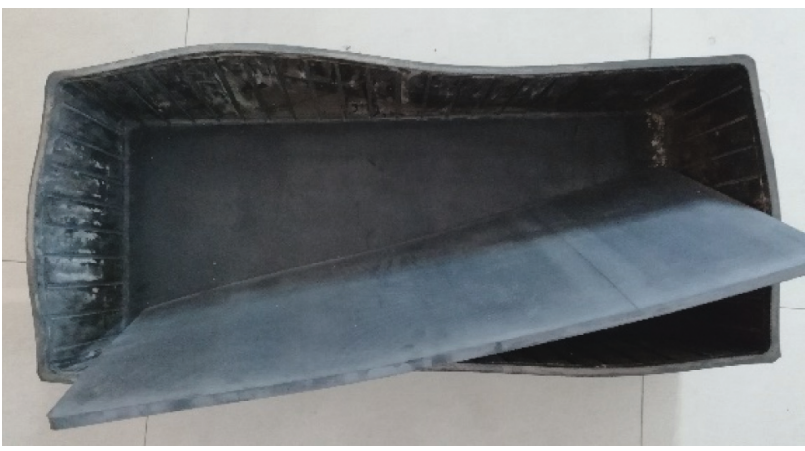

(d)

FIgURe 1: Images of bearing block and rubber boot. (a) N-LVT bearing block front view. (b) T-LVT bearing block front view. (c) N-LVT rubber boot top view. (d) T-LVT bearing block top view.

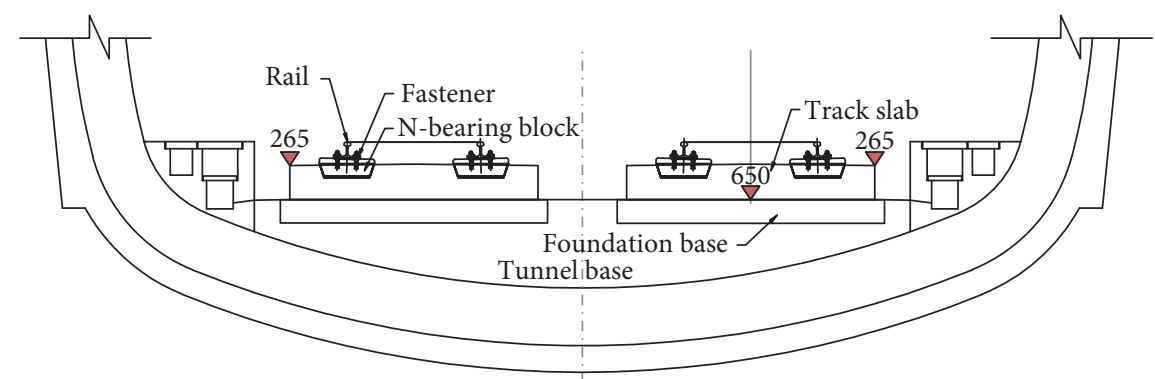

(a)

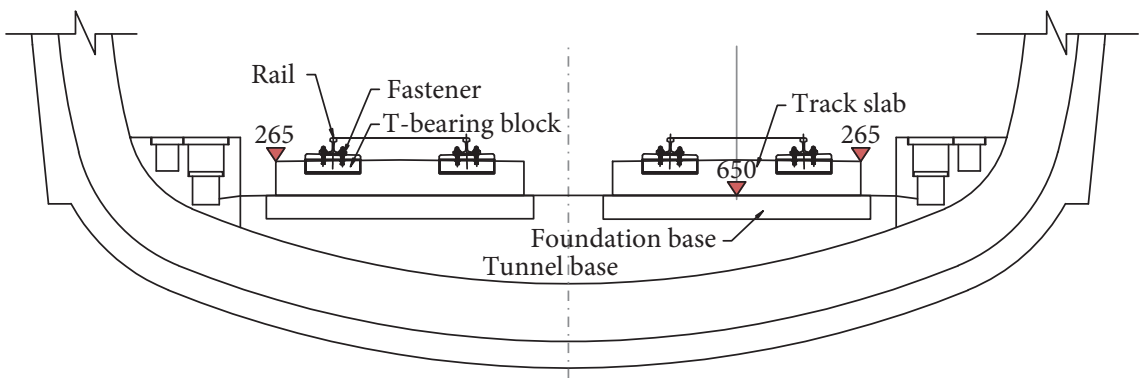

(b)

Figure 2: Cross section of LVTs in tunnel (unit: mm). (a) N-LVT cross section in tunnel. (b) T-LVT cross section in tunnel.

coefficient and the damping coefficient can be calculated using the wheel-rail impact time and the rebound fall off time.

3.2. Arrangement Plan of Measurement Points. To investigate the attenuation and transmission law of the vertical impact acceleration along the track longitudinal line, the acceleration sensors are arranged on the rails, the bearing blocks, and the track slab beneath the rail from No. 1 to No. 11, respectively. The measuring points are arranged symmetrically with the bearing block No. 6 , and the specific arrangement is shown in Figure 6. 


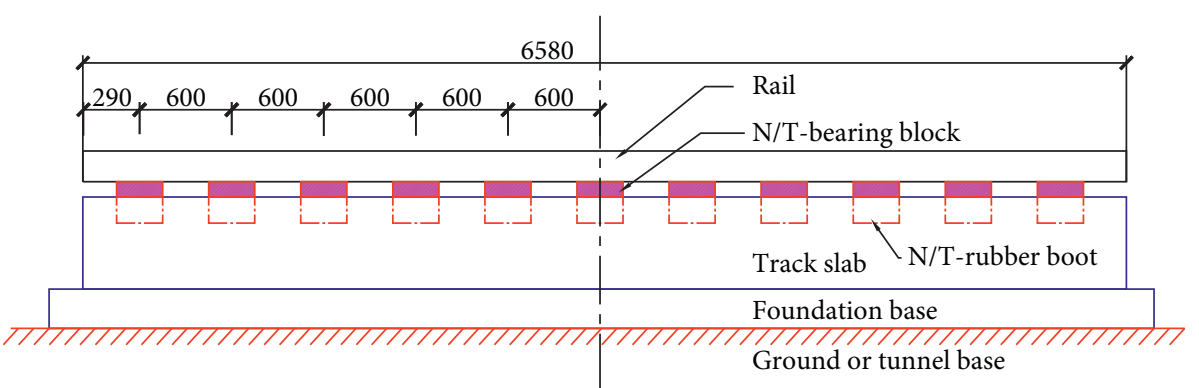

(a)

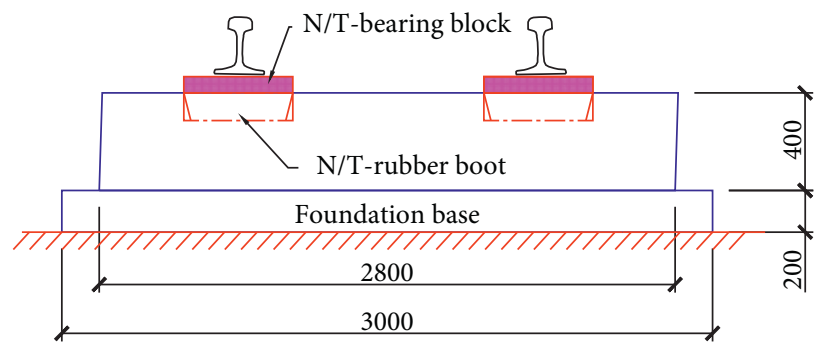

(b)

Figure 3: Full-scale test model design maps (unit: mm). (a) Front view. (b) Side view.

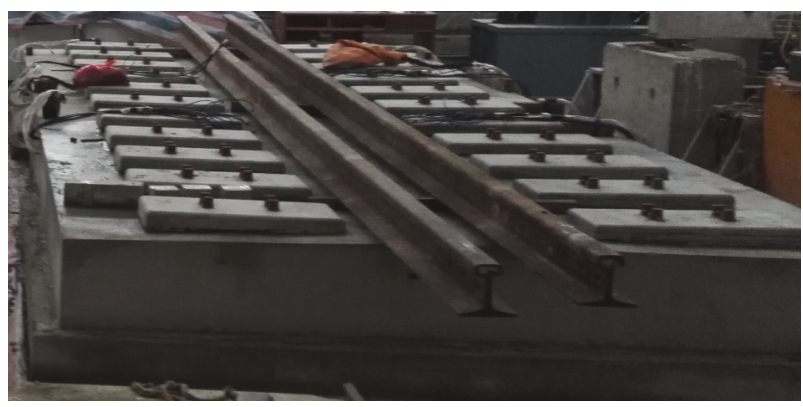

(a)

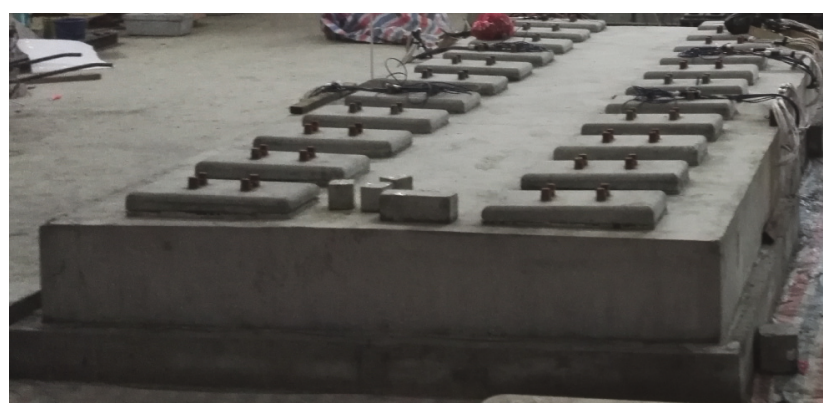

(b)

FIgURE 4: Full-scale model physical maps: (a) N-LVT and (b) T-LVT.

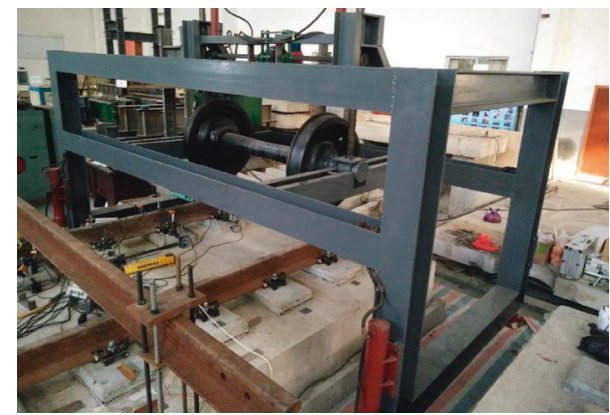

FIgURE 5: Wheelset drop impact test machine.

To investigate the attenuation and transmission law of the vertical impact acceleration along the track vertical line, the acceleration sensors are arranged on the rail, the bearing block, the track slab, the foundation base and the ground. The specific arrangement is shown in Figure 7.

To explore the attenuation and transmission law of the vertical impact acceleration along the track lateral line, the acceleration sensors are arranged on the bearing block and the track slab surface. The specific arrangement and the numbers of the acceleration sensors are shown in Figure 8.

3.3. Acquisition Instrument and Parameters. The appropriate range and sensitivity of these sensors are selected according to the location of the measuring positions. For example, the range and sensitivity of rail acceleration sensor are $\pm 10000\left(\mathrm{~m} / \mathrm{s}^{2}\right)$ and $40.2 \mathrm{mV} /\left(\mathrm{m} \cdot \mathrm{s}^{-2}\right)$, respectively, while those of the bearing block acceleration sensor are $\pm 500(\mathrm{~m} /$ $\left.\mathrm{s}^{2}\right)$ and $1050 \mathrm{mV} /\left(\mathrm{m} \cdot \mathrm{s}^{-2}\right)$, respectively. The vibration signal acquisition instrument and analysis system, IMC, are produced by Integrated Measurement and Control Company in Germany. In order to collect more accurate data, the acquisition frequency of each parameter was set to $20000 \mathrm{~Hz}$. Before the time-domain analysis, a low-pass filter was used. The cutoff frequency of the low-pass filter of the rail and the bearing block accelerations are $10000 \mathrm{~Hz}$ and $5000 \mathrm{~Hz}$, respectively. As for the acceleration of the track slab, foundation base, and ground, the cutoff frequency is $1000 \mathrm{~Hz}$. 


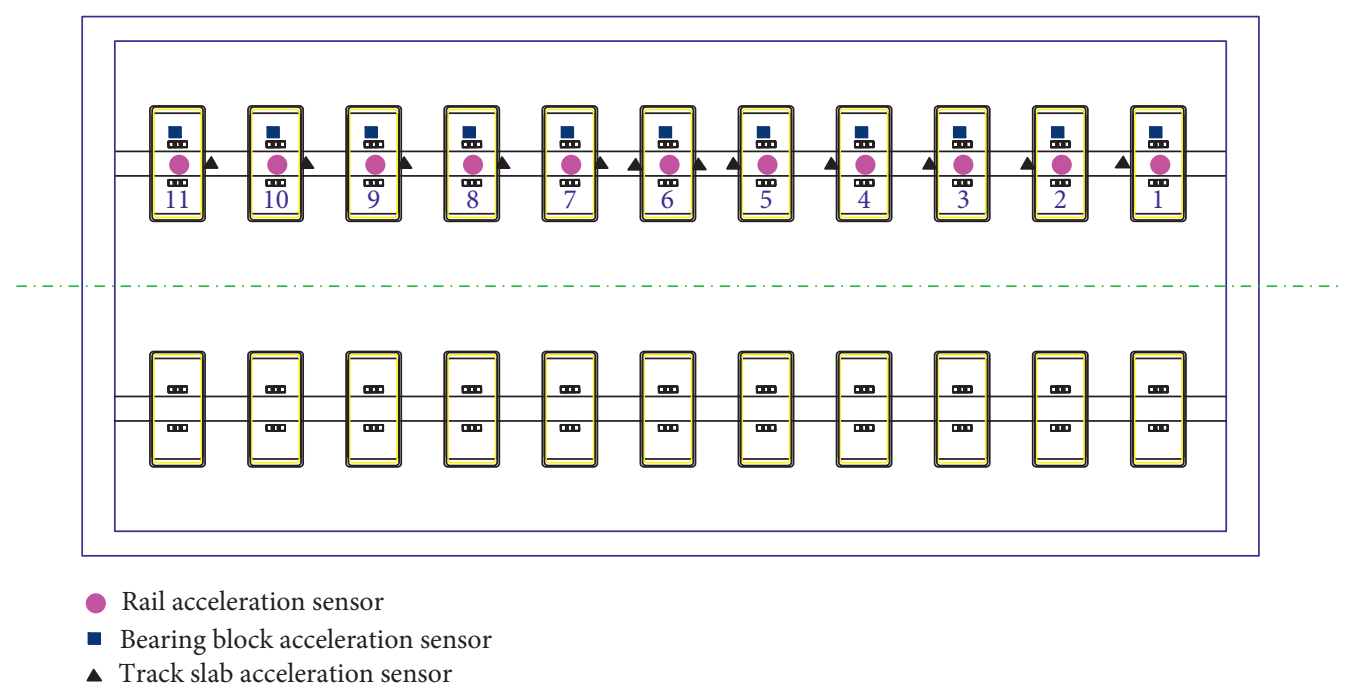

(a)

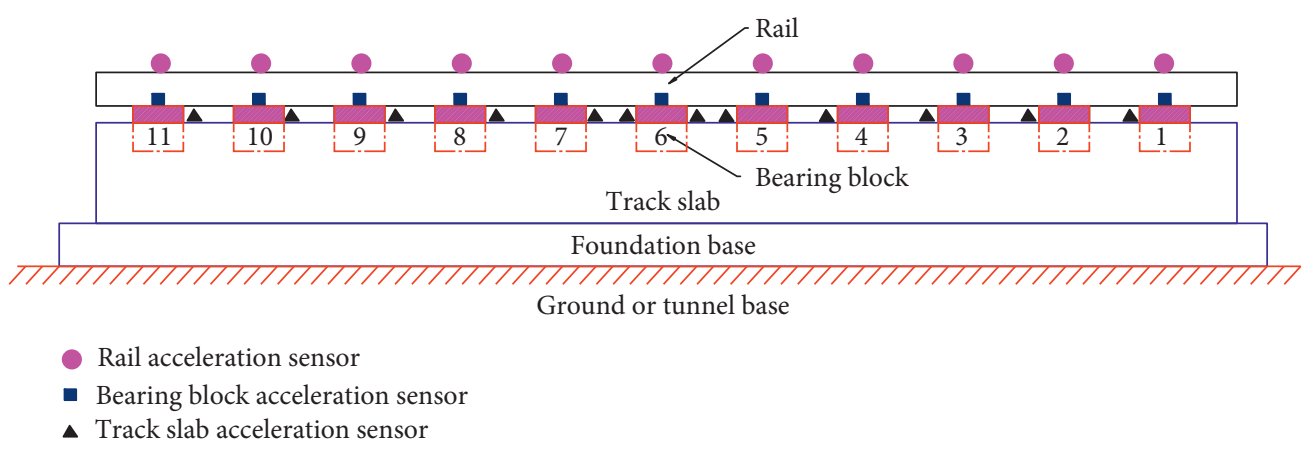

(b)

FIgURE 6: Vertical acceleration sensors arrangement along the track longitudinal line. (a) Top view. (b) Side view.

In this paper, the attenuation of the impact vibration along the longitudinal, vertical, and lateral directions of the track are analyzed from the time and frequency domains of the impact vibration signal. The time-domain analysis compares the peak value, the root mean square (RMS) value, and the period duration of the track structure impact vibration signal. Therefore, the law of impact vibration transmission and attenuation characteristics of the track structure with time are studied. The frequency-domain analysis compares the spectrum distribution of the impact vibration, the power spectral density (PSD), and the vibration level along track vertical line $\left(\mathrm{VL}_{\mathrm{z}}\right)$. Therefore, the law of the impact vibration transmission and attenuation characteristics of track structure with frequency is analyzed.

\section{Analysis of Transmission and Attenuation of Impact Vibration along the Track Longitudinal Line}

4.1. Time-Domain Analysis of the Law of Longitudinal Transmission along the Track. The acceleration peak is proportional to the surface impact force of the track structure, which can reflect the impact force level of the instantaneous track structure surface. The vibration transmission attenuation of the two LVT structures under the wheel-rail impact is analyzed by measuring the acceleration of the rails, the bearing blocks, and the track slab at the fastener from No. 1 to No. 11. According to the experimental results, the dynamic response of the track structure on both sides of the impact point is basically symmetrical, so the average measurement results on both sides of the impact point are analyzed. The peak acceleration distributions at the rails, bearing blocks, and track slab are shown in Figures 9(a)-9(c).

As shown in Figures 9(a)-9(c), the N-LVT acceleration peaks of the rail, support block, and track slab at the point of impact are reduced by $3 \%, 9.5 \%$, and $11.1 \%$ compared to the T-LVT, which means that the N-LVT can improve the stress state of the wheel-rail impact point and reduce the peak of the track structure. The N-LVT acceleration amplitude longitudinal attenuation speed is slower than the T-LVT. For the LVTs, the impact vibration on the rail, the bearing block, and the track slab reaches the same level at the distance of $1.8-2.4 \mathrm{~m}$. This shows that the N-LVT vibrational energy is transmitted more along the longitudinal direction of the track.

The velocities are obtained by numerically integrating the acceleration signals using a high-pass digital filter with a cutoff frequency of $1 \mathrm{~Hz}$ to eliminate the DC component and 


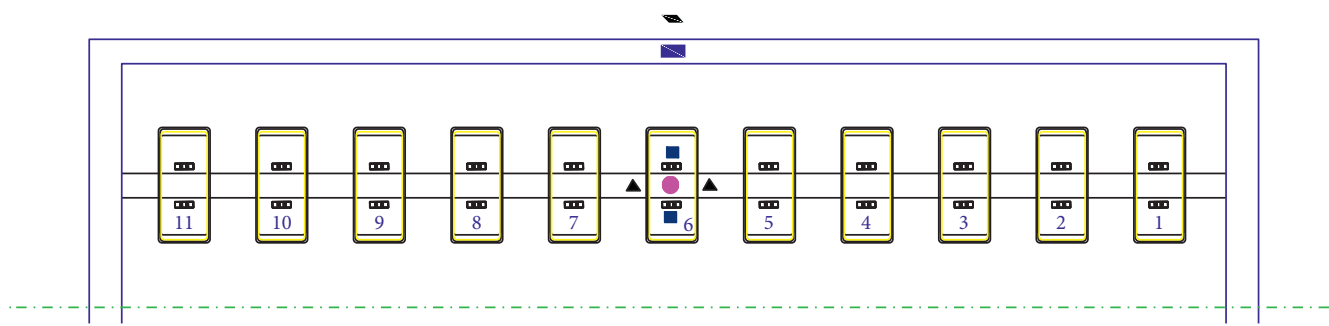

Rail acceleration sensor

- Bearing block acceleration sensor

- Track slab acceleration sensor

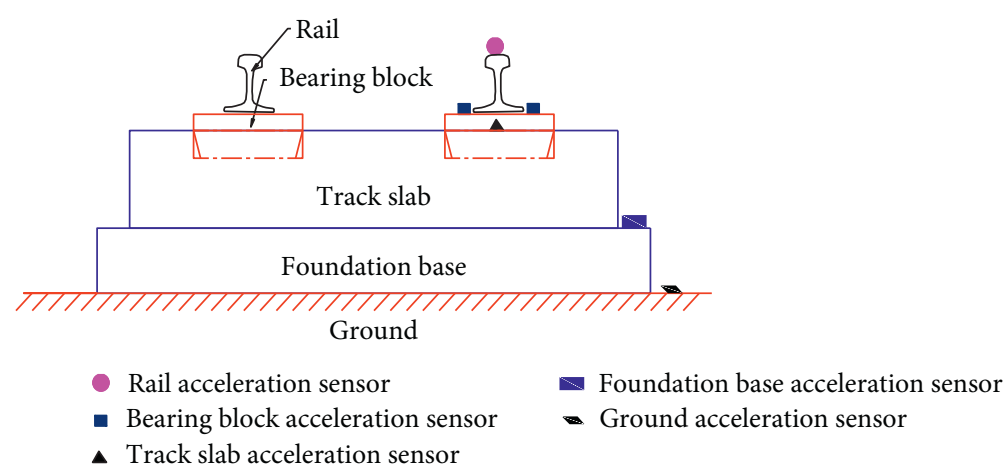

(b)

Figure 7: Vertical acceleration sensors arrangement along the track vertical line. (a) Top view. (b) Side view.

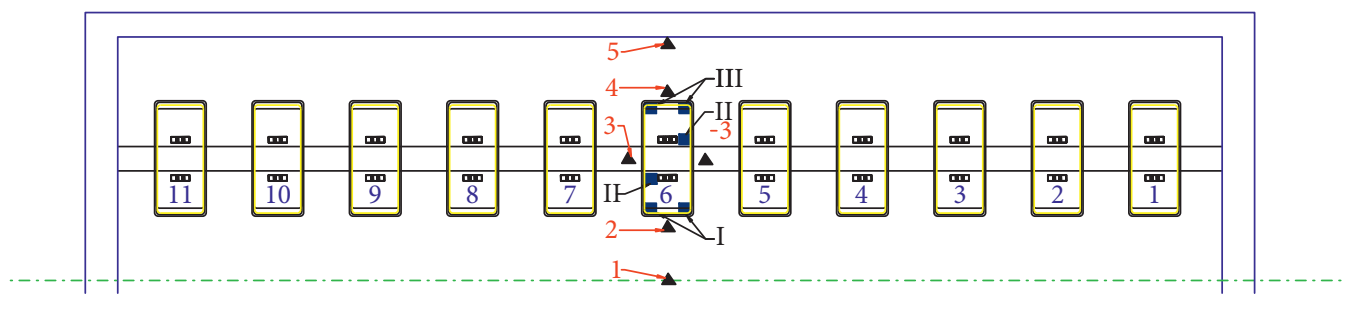

- Bearing block acceleration sensor

- Track slab acceleration sensor

(a)

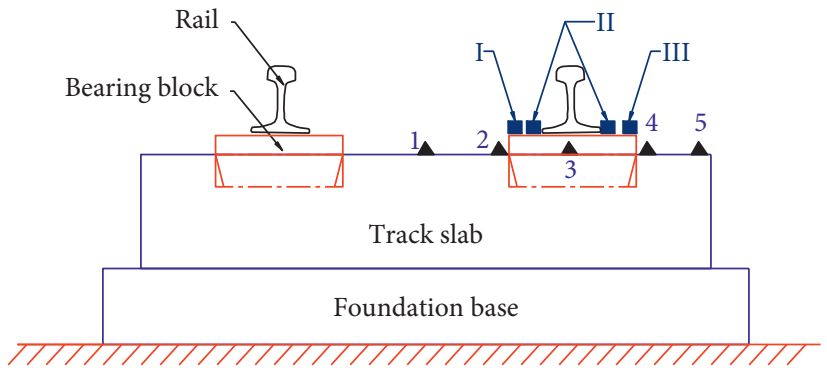

Ground

- Bearing block acceleration sensor

- Track slab acceleration sensor

(b)

Figure 8: Vertical acceleration sensors arrangement along the track lateral line. (a) Top view. (b) Side view. 


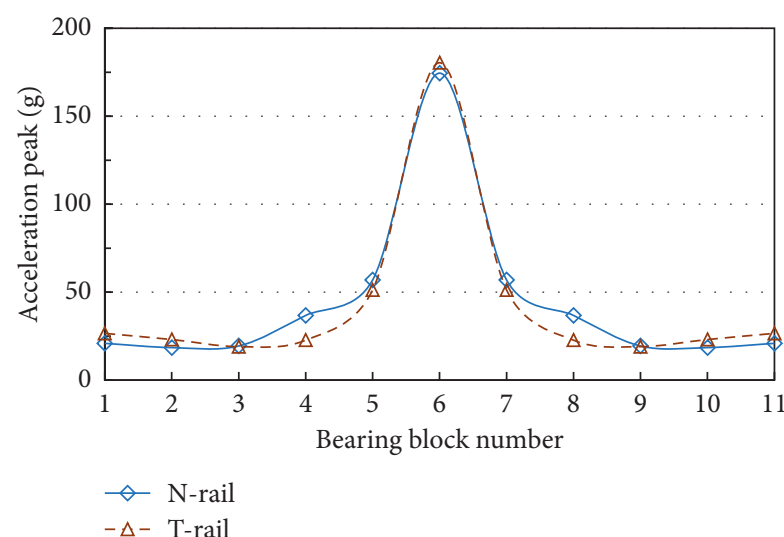

(a)

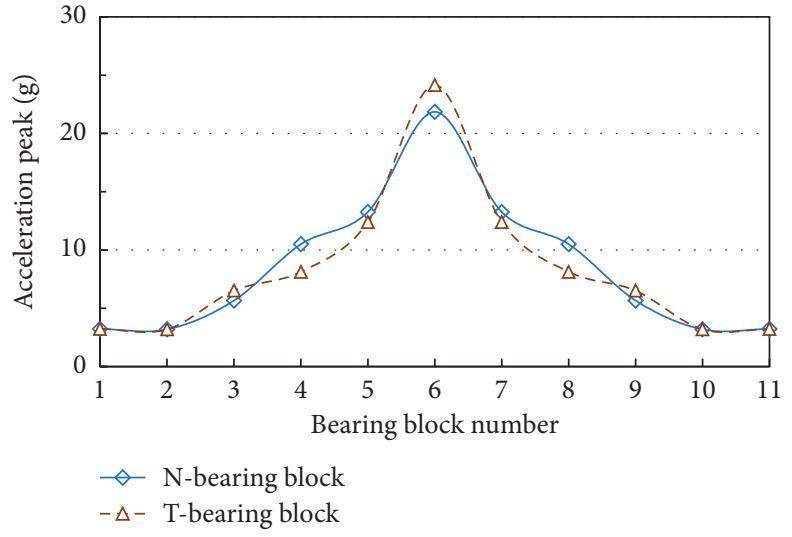

(b)

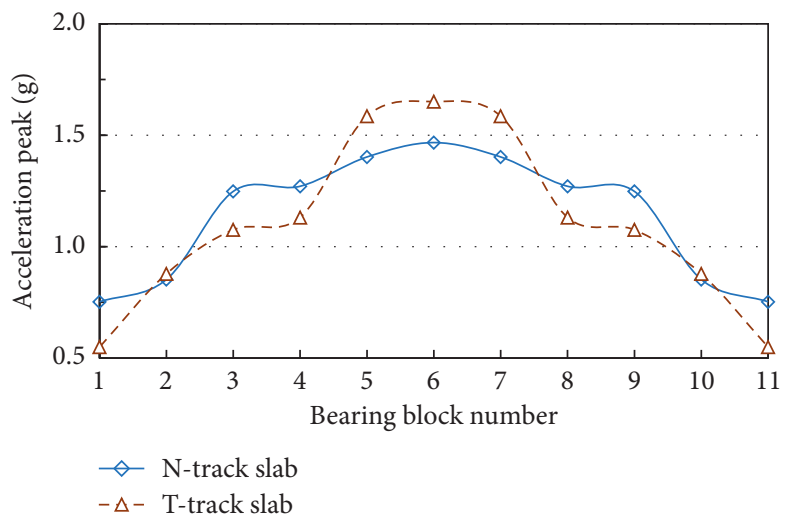

(c)

Figure 9: Longitudinal acceleration distribution peak along the track. (a) Rail acceleration peak. (b) Bearing block acceleration. (c) Track slab acceleration peak.

avoid baseline drifting. The velocity and acceleration curves at the other fastener are basically the same as No. 6 , so the attenuation curves of the bearing block and the track slab at the point of the wheelset-rail impact are analyzed. The vertical vibration velocity and the acceleration time-domain curves of the bearing block and the track slab are shown in Figure 10.

As shown in Figure 10(a), the peak distribution of the vibration velocity of the N-LVT bearing block and the track slab is $240.1 \mathrm{~mm} / \mathrm{s}$ and $16.2 \mathrm{~mm} / \mathrm{s}$, respectively, which is $3.3 \%$ and $14.8 \%$ smaller than that of the T-LVT. As shown in Figure 10(b), the decay time of the first period and the total attenuation time for the N-LVT are $33.97 \mathrm{~ms}$ and $118.67 \mathrm{~ms}$, respectively. For the T-LVT, the values are $46.53 \mathrm{~ms}$ and $97.85 \mathrm{~ms}$, respectively, which is $37.0 \%$ and $21.3 \%$ longer than that of the N-LVT. The N-LVT has a shorter decay duration and a lower vibration peak, which indicates that the N-LVT can reduce the impact on the track structure when the wheelset dropping impact occurs.

4.2. Frequency-Domain Analysis of the Law of Longitudinal Transmission along the Track. The Fourier transform is used to convert the time-domain signal into the frequency domain to obtain the PSD distribution curve of the vibration signals at the rail, the bearing block, and the track slab at each fastener. A random signal usually has finite average power and is characterized by an average power spectral density as follows:

$$
\operatorname{PSD}_{\mathrm{f}}(w)=\lim _{T \longrightarrow \infty} \frac{\left|F_{X_{T}}(w)^{2}\right|}{2 T},
$$

where $F_{X_{T}}(w)$ represents the fast Fourier transformation (FFT) output of a random vibration signal and $T$ is the total duration of the input signal, 0.15 seconds is used in this paper. The analysis results of the vibration signal at the rail, the bearing block, and the track slab from No. 1 to No. 6 are shown in Figures 11(a)-11(f).

As shown in Figures 11(a)-11(f), the PSD distribution of the two LVTs is different when the wheel-rail impact occurs. The PSD of the N-LVT rail, which is concentrated on the $590-670 \mathrm{~Hz}$, is lower than $600-700 \mathrm{~Hz}$ of the T-LVT, and the number of N-LVT peaks in this frequency band is lower and less than that of the T-LVT. The PSD distribution of the bearing block concentrates in the frequency ranges of $80-$ $120 \mathrm{~Hz}$ and $220-320 \mathrm{~Hz}$ for the N-LVT and $80-130 \mathrm{~Hz}$ and $200-260 \mathrm{~Hz}$ for the T-LVT. The PSD distribution of the N-LVT track slab is mainly concentrated near $150 \mathrm{~Hz}$ and $250 \mathrm{~Hz}$, while that of the T-LVT is mainly distributed in the 

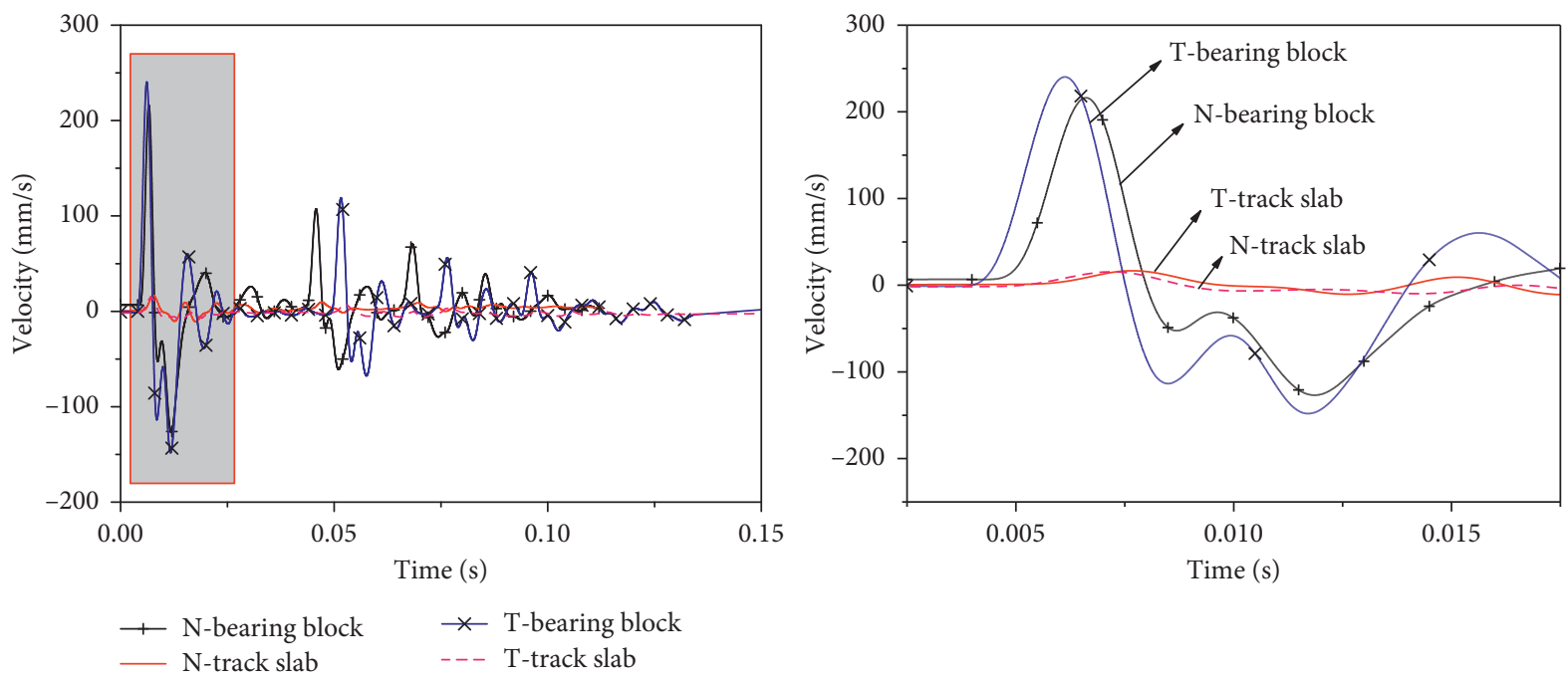

(a)
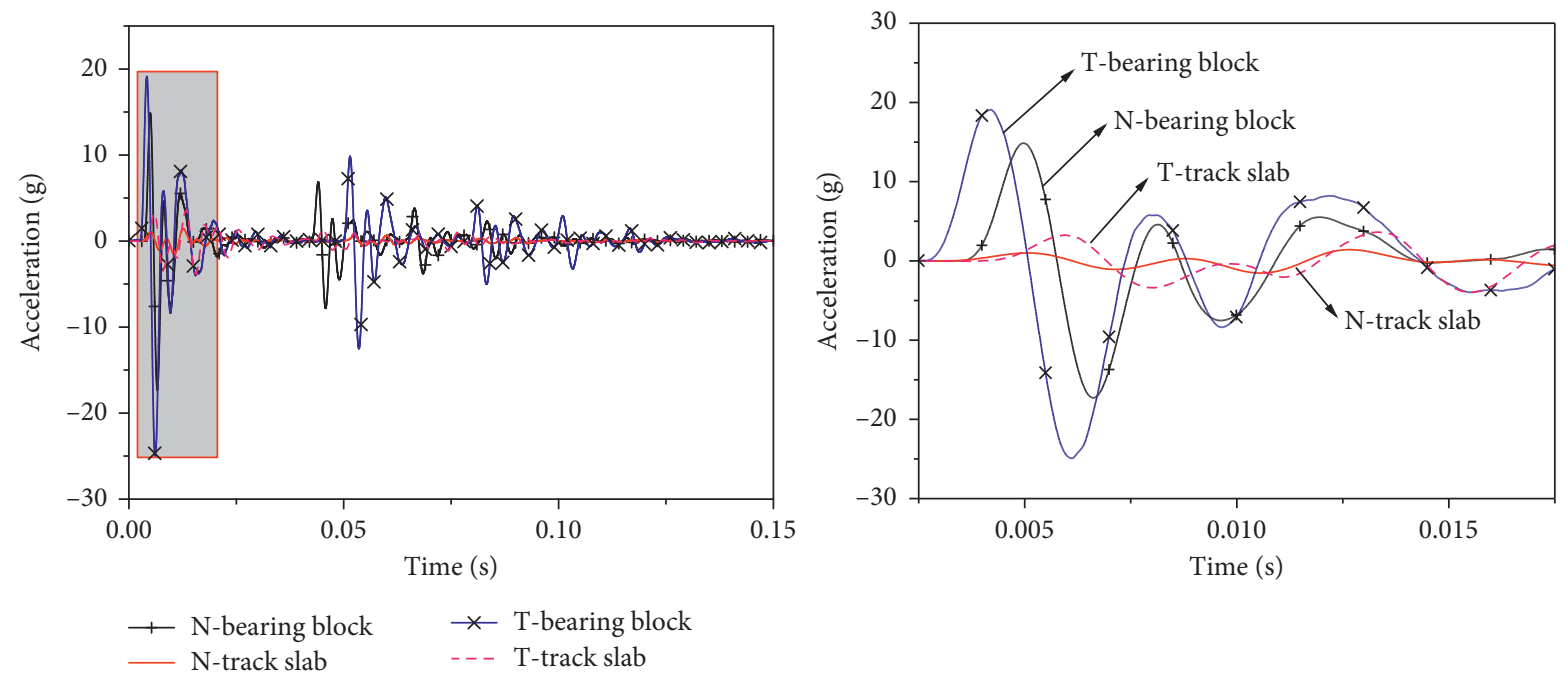

(b)

Figure 10: Velocity and acceleration time-history curves at the fastener No. 6. (a) Velocity: (left) full chart; (right) enlarged details. (b) Acceleration: (left) full chart; (right) enlarged details.

frequency bands of $100 \mathrm{~Hz}, 130 \mathrm{~Hz}$, and $230-290 \mathrm{~Hz}$. The frequency distribution of the N-LVT is concentrated more than that of the T-LVT, while the vibration level is lower.

The PSD of the N-LVT amplitude decays faster and has lower frequency compared to the T-LVT, when the vibration traverses from the fastener No.6 (track slab center) to the fastener No. 1 (track slab end), indicating that the N-LVT can reduce the impact vibration along the longitudinal direction of the line faster than the T-LVT.

\section{Analysis of the Transmission and Attenuation of Impact Vibration along the Track Vertical Line}

5.1. Time-Domain Analysis of the Law of Vertical Transmission along the Track. The time-domain curve of each track structure under the impact of the dropping wheelset is shown in Figures 12(a)-12(e). The two LVTs structures are attenuated to lower vibration levels after 3-4 cycles. The vibration amplitude of the N-LVT fourth cycle is close to the normal; the N-LVT vibration cycle is obviously shorter than that of the T-LVT. The peak attenuation amplitude of the N-LVT bearing block and the track slab is larger than that of the T-LVT, and the difference between the rail and the track slab is not significant, indicating that the N-LVT can attenuate the structural vibration more quickly and reduce the vibration level of the track structure more dramatically.

The vertical transmission and attenuation law of the impact vibration can be obtained by analyzing the acceleration amplitude of the impact acceleration at each track structure component of the fastener No. 6. The average acceleration and the RMS at the fastener from No. 1 to No. 6 are shown in Figure 13. The acceleration RMS values are computed with 

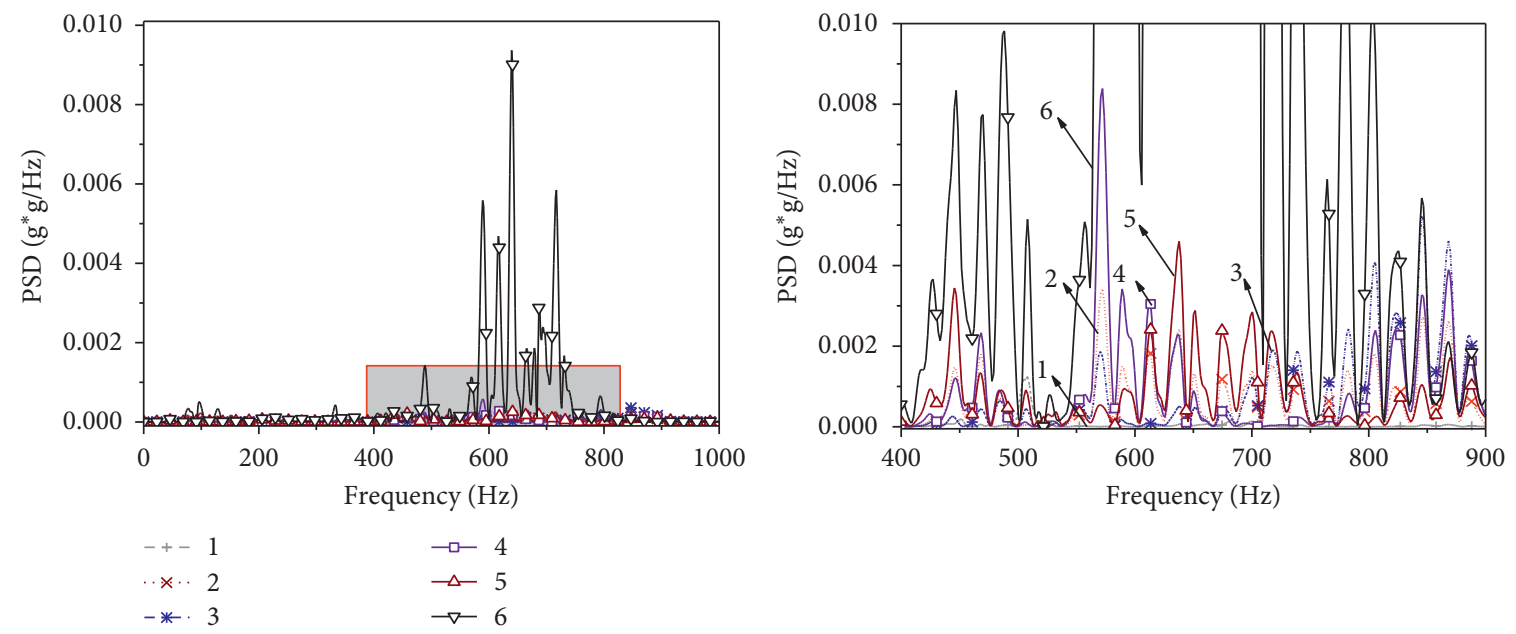

(a)
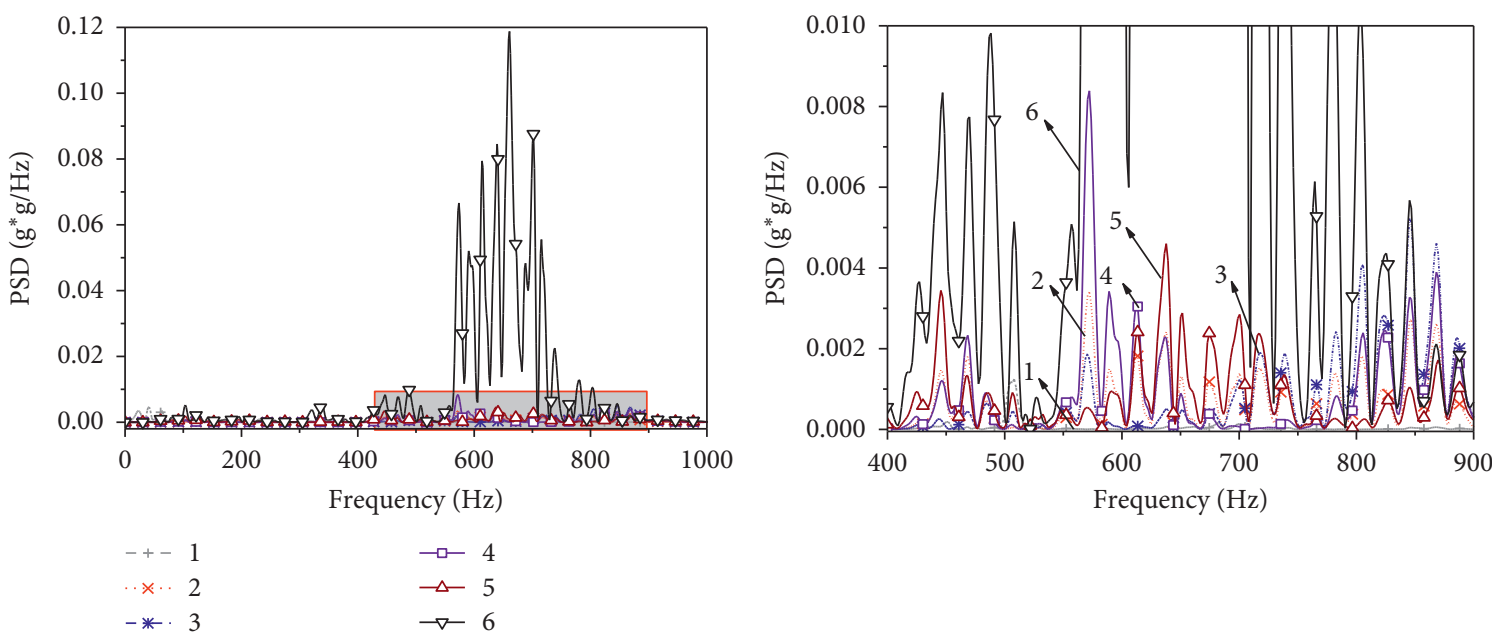

(b)
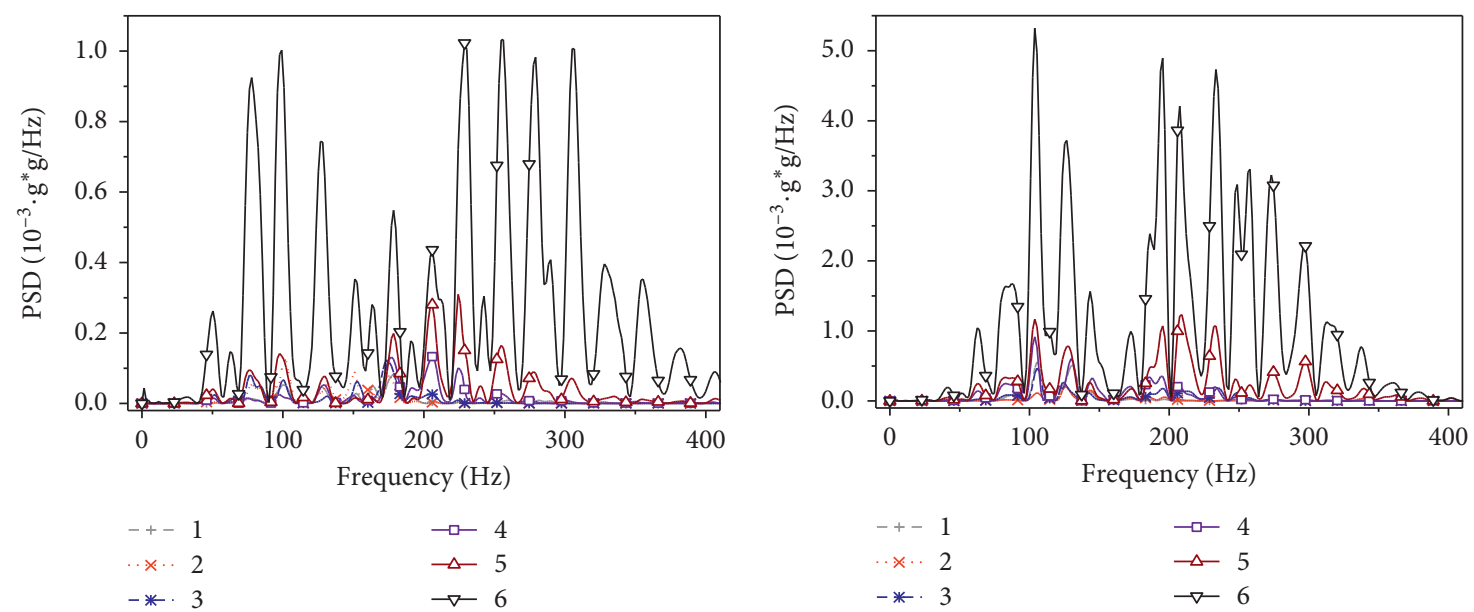

(c)

(d)

Figure 11: Continued. 


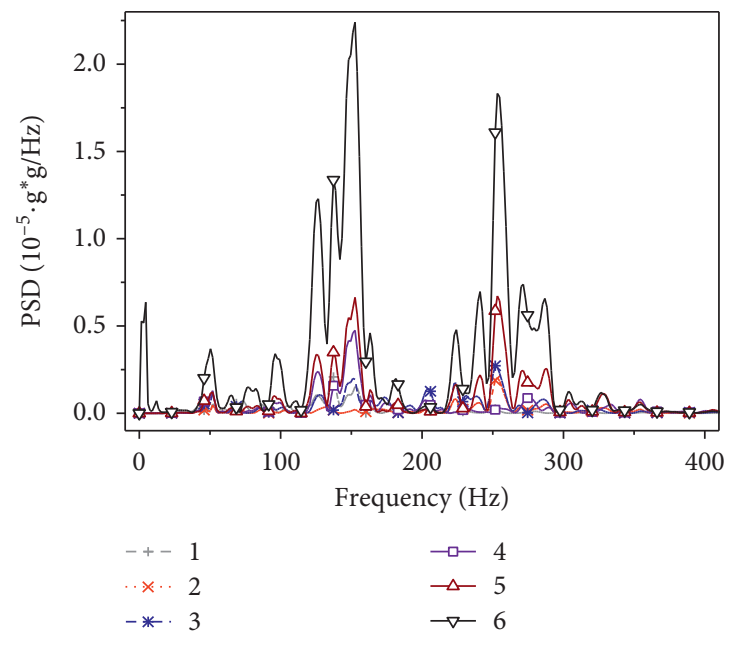

(e)

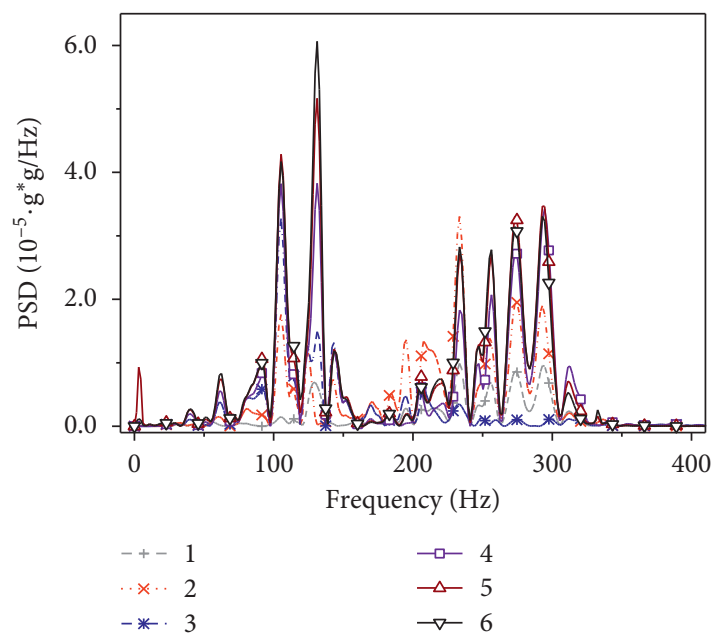

(f)

Figure 11: Track components PSD. (a) N-LVT rail: (left) full chart; (right) enlarged details of the PSD. (b) T-LVT rail: (left) full chart; (right) enlarged details of the PSD. (c) N-LVT bearing block. (d) T-LVT bearing block. (e) N-LVT track slab. (f) T-LVT track slab.

$$
a_{\mathrm{RMS}}=\sqrt{\frac{1}{t_{0}} \int_{0}^{t_{0}} a^{2}(t) d t},
$$

where $t_{0}$ is the width of the time window; 0.15 seconds is used in this paper.

It can be seen from Figures 13(a) and 13(b) that the difference between the peak value and the RMS of the rails and the ground of the two LVT structures is obvious. The peak value and the RMS of the N-LVT in the bearing block, the track slab, and the ground are smaller than that of the T-LVT. This is extremely obvious at the ground, where the reduction is more than $30 \%$, which is beneficial for reducing the vibration level of the tunnel base and the lining structure.

Using the wheel-rail impact experiment results of different dropping wheelset heights, the two structural elastic coefficients $K$ and the damping coefficients $C$ are calculated as shown in Table 1. As can be seen from Table 1, the elastic coefficients of the N-LVT and the T-LVT are $37.7-45.2 \mathrm{kN} /$ $\mathrm{mm}$ and $47.4-55.2 \mathrm{kN} / \mathrm{mm}$, respectively, and the damping coefficients are $277.5-324.9 \mathrm{kN} \mathrm{s} / \mathrm{m}$ and $205.4-281.9 \mathrm{kN} \mathrm{s} / \mathrm{m}$, respectively. Compared to the T-LVT, the overall elastic modulus of the N-LVT decreases on average by $21.1 \%$, while the damping coefficient increases on average by $16.7 \%$, indicating that the N-LVT is more advantageous for attenuating the wheel-rail impact vibration.

5.2. Frequency-Domain Analysis of the Law of Vertical Transmission along the Track. When the impact occurs at the wheel and rail, the attenuation law of the main frequency of the vibration of different components can be determined by studying the vertical attenuation and transmission law of the vibration along the line. Measures can then be taken to reduce the vibration and vibration isolation, as well as the damage caused to the track and tunnel structures. The $1 / 3$ octave calculation results at each track structure are shown in the Figures 14(a)-14(e).
It can be seen from Figure 14 that the rail energy is distributed at $630 \mathrm{~Hz}$, and the variation of the highfrequency vibration range is basically the same. The main peak of the vibration is $630 \mathrm{~Hz}$, with the subpeak of $1600 \mathrm{~Hz}$ for the N-LVT and $2000 \mathrm{~Hz}$ for the T-LVT. The main frequency of the N-LVT is reduced; the impact vibration is transmitted from the rail to the ground, and the $250 \mathrm{~Hz}$ vibration is transmitted to the ground with a high peak. The $20-100 \mathrm{~Hz}$ vibration of the N-LVT is better than that of the T-LVT, but $50 \mathrm{~Hz}$ may be overlapped with the main vibration frequency of the track slab to cause resonance. The foundation base and the ground $\mathrm{VL}_{\mathrm{z}}$ of the N-LVT are generally smaller than that of the T-LVT, indicating that the $\mathrm{N}$-LVT can reduce the impact vibration on the lower structure and play a better damping effect.

The vibration measurement can be carried out according to the code Mechanical Vibration and Shock-Evaluation of Human Exposure to Whole-body Vibration (ISO 2631-11997) [30] and the Chinese code Measurement Method of Environmental Vibration of Urban Area (GB/T 13441-2007) [31]. According to [30, 31], the vibration level insertion loss is used to evaluate the vibration reduction effects. The vibration acceleration level (VAL) is calculated using

$$
\mathrm{VAL}=20 * \log \left(\frac{a}{a_{0}}\right),
$$

where $a$ is the vibration acceleration RMS, and $a_{0}$ is the reference acceleration.

The $\mathrm{VL}_{\mathrm{z}}$ is the vertical ground vibration acceleration level obtained by the $W_{\mathrm{K}}$ weighting factor correction. The $\mathrm{VAL}$ is calculated using

$$
\mathrm{VL}_{\mathrm{z}}=10 * \lg \left(\sum_{i=1}^{n} 10^{0.1 *\left(\mathrm{VAL}_{i}+W_{\mathrm{K} i}\right)}\right) \text {, }
$$



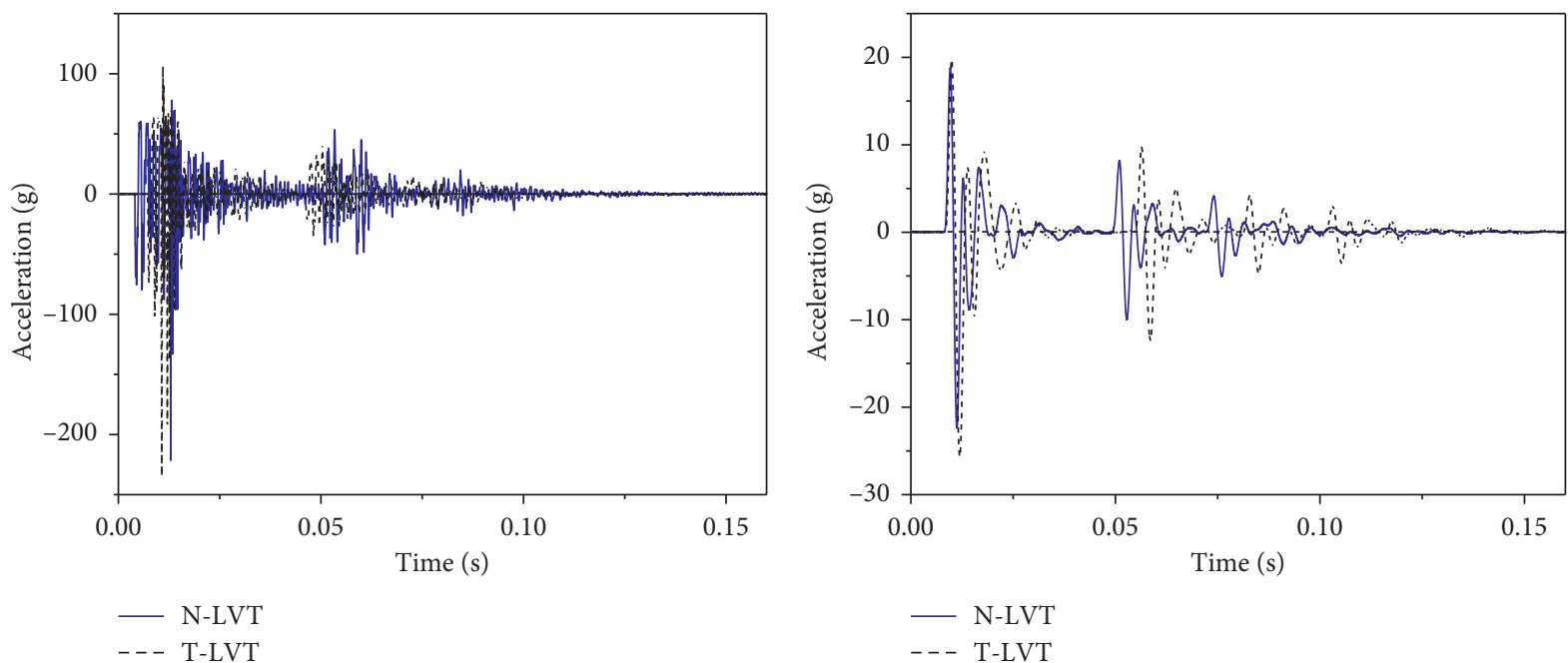

(a)

(b)

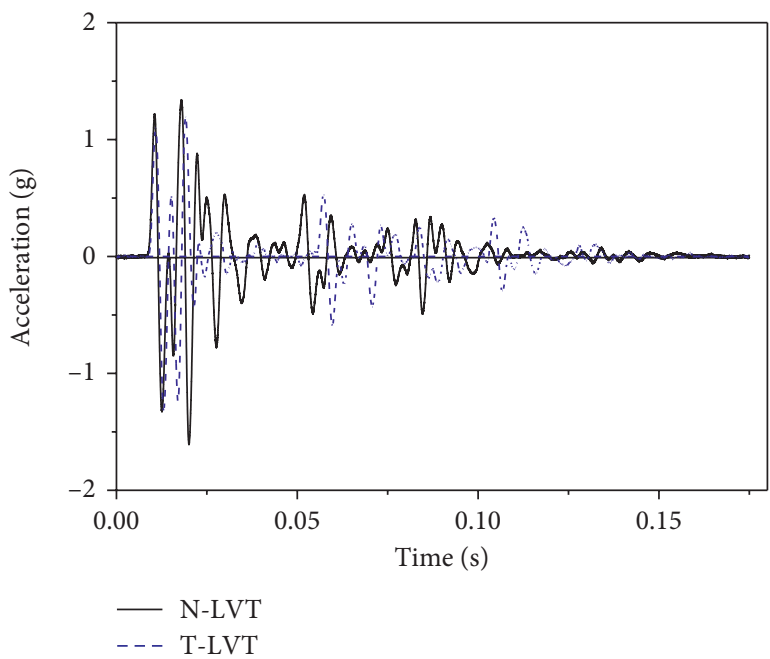

(c)

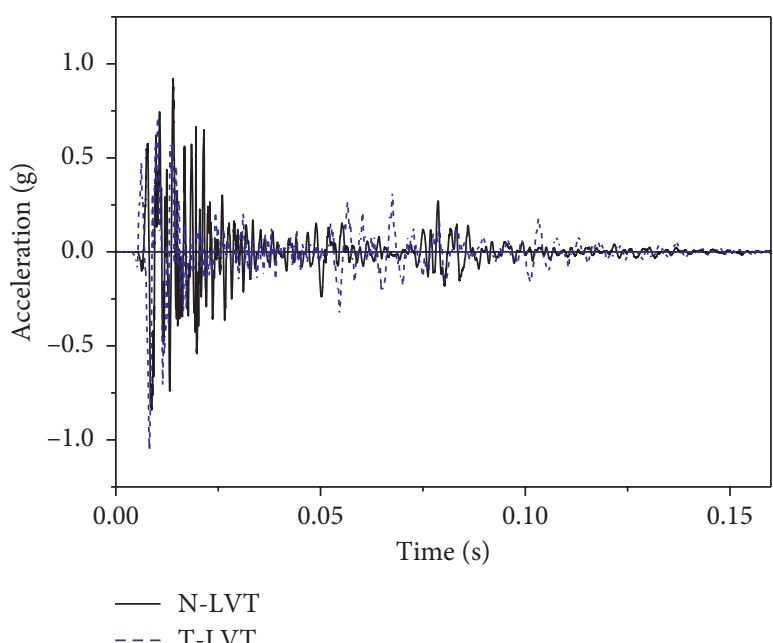

(d)

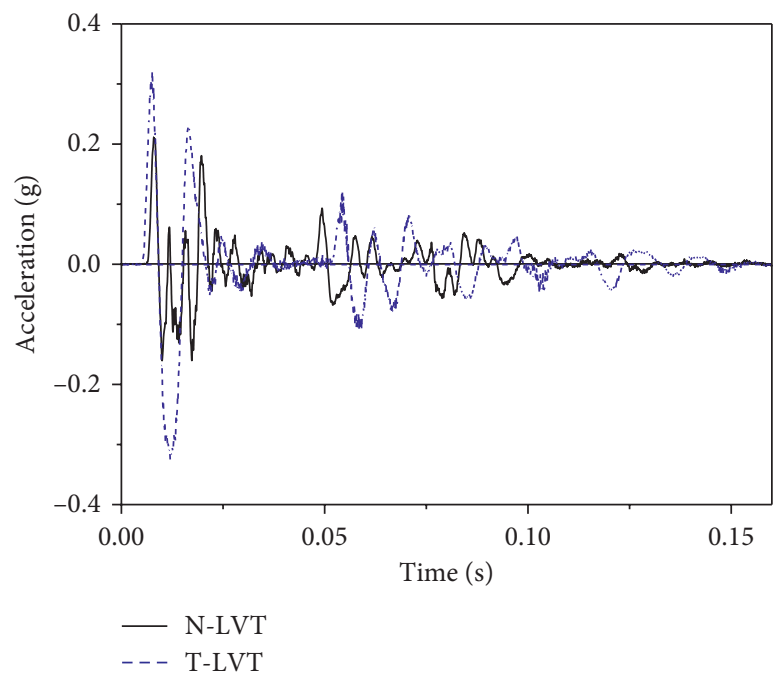

(e)

Figure 12: Comparison of vertical time-history curve of the track components. (a) Rail. (b) Bearing block. (c) Track slab. (d) Foundation base. (e) Ground. 


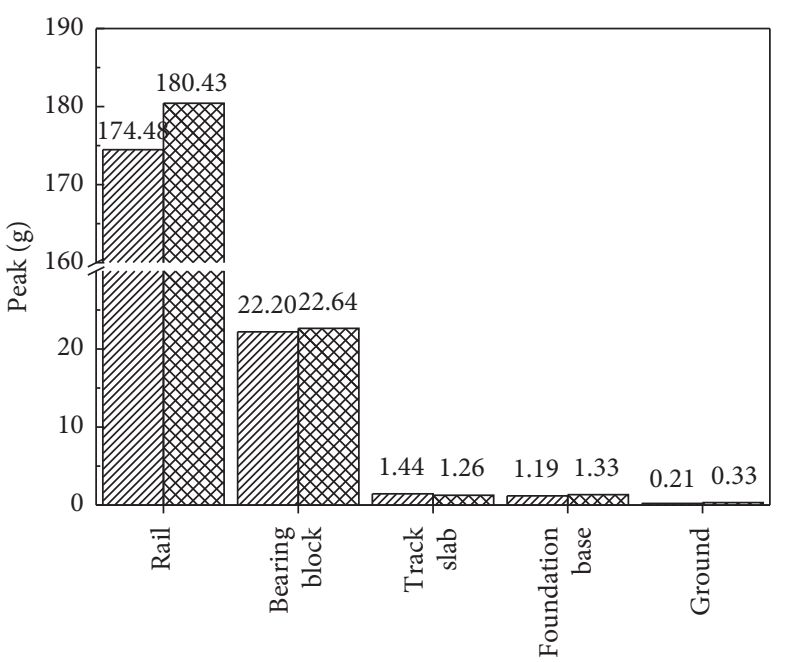

N-LVT

T-LVT

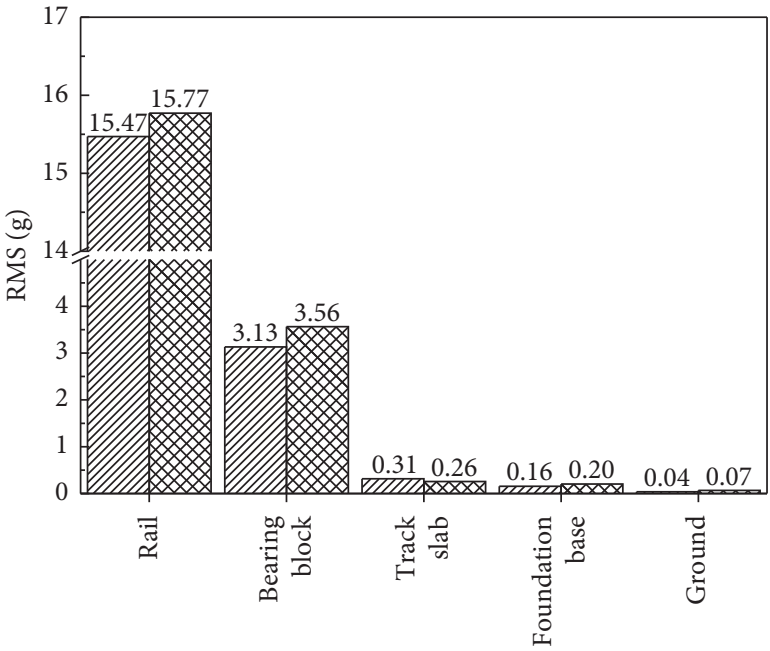

$\mathrm{N}-\mathrm{LVT}$

T-LVT

(a)

(b)

FIgURE 13: Track components acceleration peak and RMS. (a) Acceleration peak. (b) Acceleration RMS.

TABLE 1: Elastic coefficient and damping coefficient for the N-LVT and T-LVT.

\begin{tabular}{|c|c|c|c|c|c|c|c|c|}
\hline \multirow[t]{2}{*}{ Dropping height (mm) } & \multicolumn{2}{|c|}{$\begin{array}{l}\text { Continuous action } \\
\text { time } T_{0}(\mathrm{~ms})\end{array}$} & \multicolumn{2}{|c|}{ Intervals $2 t_{1}(\mathrm{~ms})$} & \multicolumn{2}{|c|}{$\begin{array}{c}\text { Elastic coefficient } K \\
(\mathrm{kN} / \mathrm{mm})\end{array}$} & \multicolumn{2}{|c|}{$\begin{array}{c}\text { Damping coefficient } \\
C(\mathrm{kN} \cdot \mathrm{s} / \mathrm{m})\end{array}$} \\
\hline & N-LVT & T-LVT & N-LVT & T-LVT & N-LVT & T-LVT & N-LVT & T-LVT \\
\hline 10 & 12.5 & 11.6 & 20.5 & 29.5 & 39.5 & 54.4 & 284.8 & 231.4 \\
\hline 20 & 12.8 & 11.7 & 29.1 & 34.6 & 37.7 & 47.4 & 277.5 & 263.3 \\
\hline 30 & 11.9 & 11.3 & 38.4 & 41.5 & 45.2 & 52.0 & 283.3 & 281.9 \\
\hline
\end{tabular}

where $\mathrm{VAL}_{i}$ is the $i$ th vibration acceleration level, $W_{\mathrm{K} i}$ is the $i$ th weighting factor, and $n$ is the number of $1 / 3$ octave calculation points.

The insertion loss is the difference between the vibration levels with different vibration control measures, which is defined as

$$
I_{1}=20 \log \frac{a_{\mathrm{T}}}{a_{\mathrm{N}}}
$$

where $a_{\mathrm{T}}$ is the vibration response of T-LVT and $a_{\mathrm{N}}$ is the vibration response with $\mathrm{N}$-LVT. If $I_{1}>0$, it indicates that there is a vibration reduction effect.

Taking base acceleration as $10^{-6} \mathrm{~m} / \mathrm{s}^{2}$, the insertion loss can be calculated as

$$
\begin{aligned}
& I_{1}=20 \log \frac{a_{\mathrm{T}}}{a_{\mathrm{N}}}=20 \log \left(\frac{a_{\mathrm{T}}}{a_{0}} \cdot \frac{a_{0}}{a_{\mathrm{N}}}\right)=20 \log \frac{a_{\mathrm{T}}}{a_{0}}-20 \log \frac{a_{\mathrm{N}}}{a_{0}}, \\
& I_{1}=\mathrm{VL}_{\mathrm{z}-\mathrm{T}}-\mathrm{VL}_{\mathrm{z}-\mathrm{N}} .
\end{aligned}
$$

The $\mathrm{VL}_{\mathrm{z}}$ of each track structural component is shown in Table 2. The difference between the two LVTs in the rail, the bearing block, and the track slab is small, but the damping effect of the N-LVT on the foundation base and the ground is
$6.0 \mathrm{~dB}$ and $7.1 \mathrm{~dB}$, respectively, indicating that the N-LVT track structure can better attenuate the impact vibration and reduce the track vibration. The LVT structure reduces the sound source intensity of the secondary noise, which is beneficial for the protection of the track and the tunnel lining structure.

\section{Analysis of Impact Vibration Transmission and Attenuation along the Track Lateral Line}

This section analyzes the vibration signals on the surfaces of the bearing block and the track slab to obtain their distribution characteristics and the transmission attenuation law in the track lateral line. Such analysis can strengthen the design of the weak links of the track components.

6.1. Time-Domain Analysis of the Law of Lateral Transmission along the Track. Optimized on the basis of the T-LVT bearing block design, the N-LVT bearing block increases the short side slope so that the surface acceleration distribution of the bearing block can be studied. The acceleration average and the acceleration RMS of the bearing block surface are shown in Figures 15(a) and 15(b). 

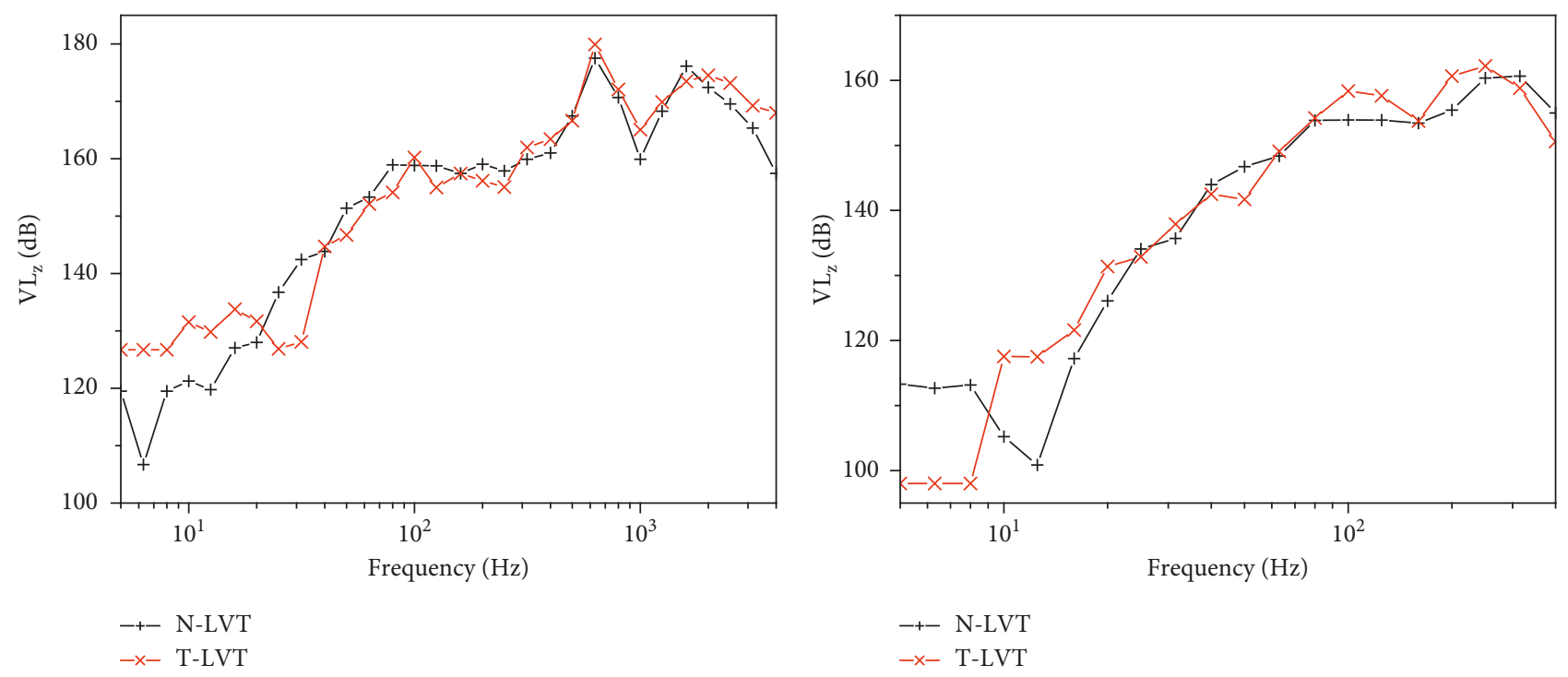

(a)
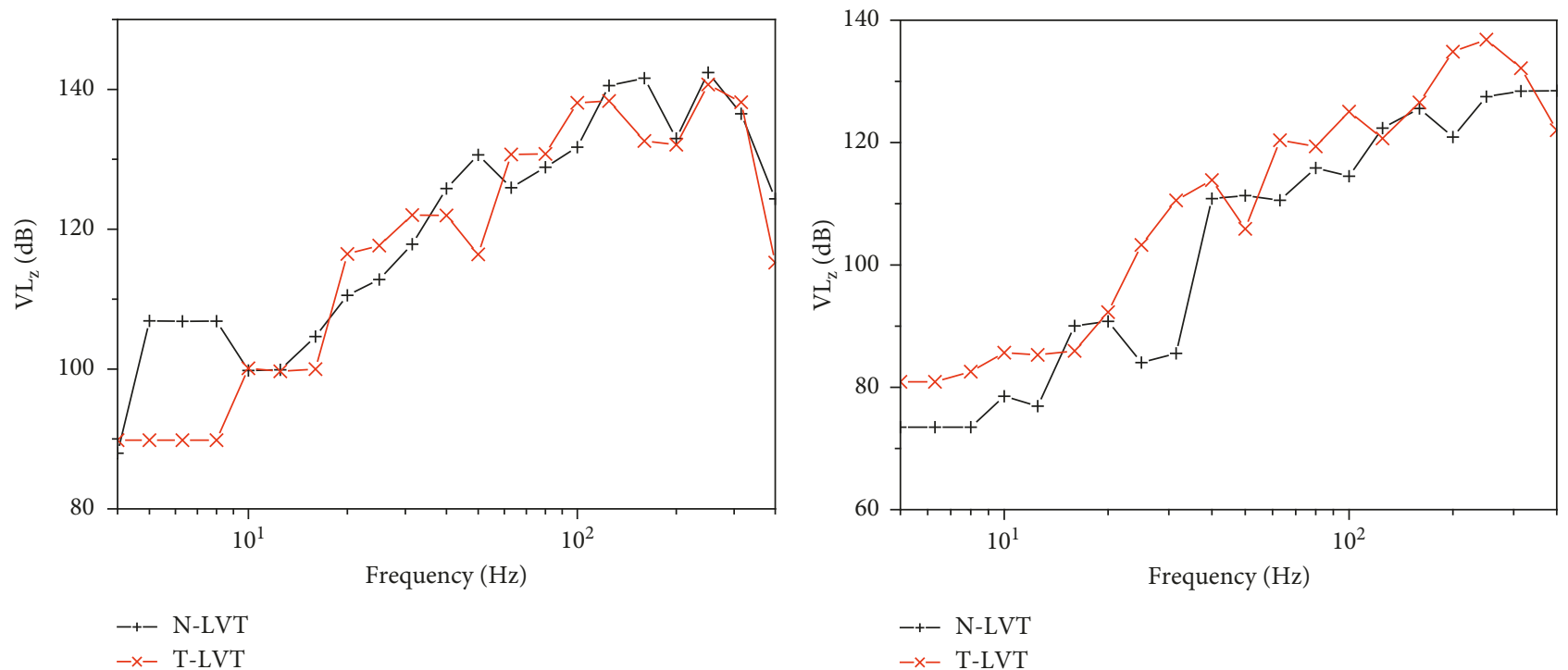

(c)

(d)

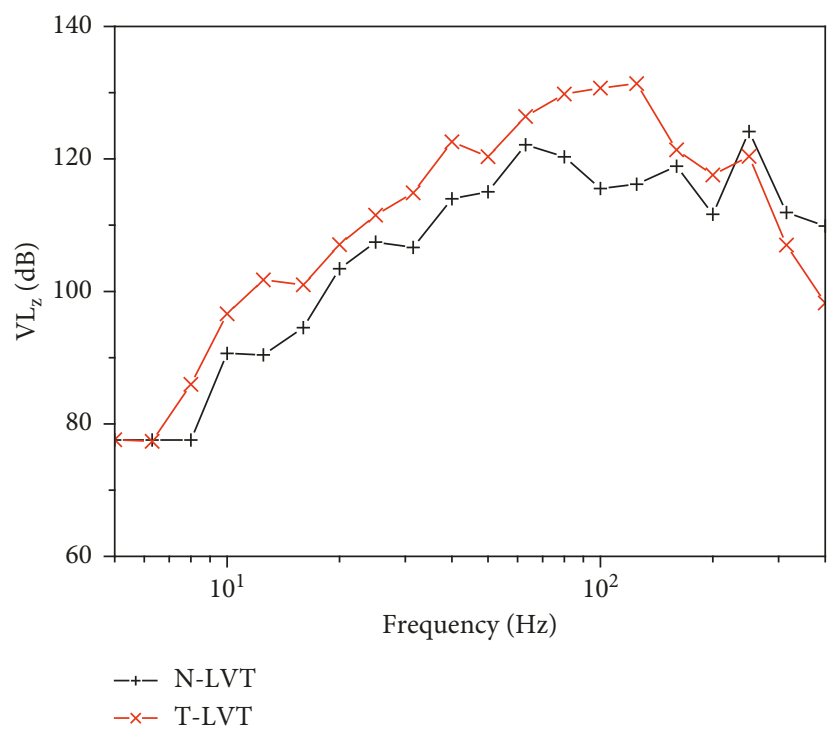

(e)

Figure 14: 1/3 octave curve of the track components. (a) Rail. (b) Bearing block. (c) Track slab. (d) Foundation base. (e) Ground. 
TABLE 2: $\mathrm{VL}_{\mathrm{z}}$ and insertion loss for each component.

\begin{tabular}{|c|c|c|c|c|c|}
\hline \multirow{2}{*}{ Type } & \multicolumn{5}{|c|}{ Track components (dB) } \\
\hline & Rail & Bearing block & Track slab & Foundation base & Ground \\
\hline N-LVT & 182.0 & 166.0 & 147.4 & 134.3 & 125.3 \\
\hline T-LVT & 183.5 & 167.5 & 145.8 & 140.3 & 132.4 \\
\hline Insertion loss & 1.5 & 1.5 & -1.6 & 6.0 & 7.1 \\
\hline
\end{tabular}

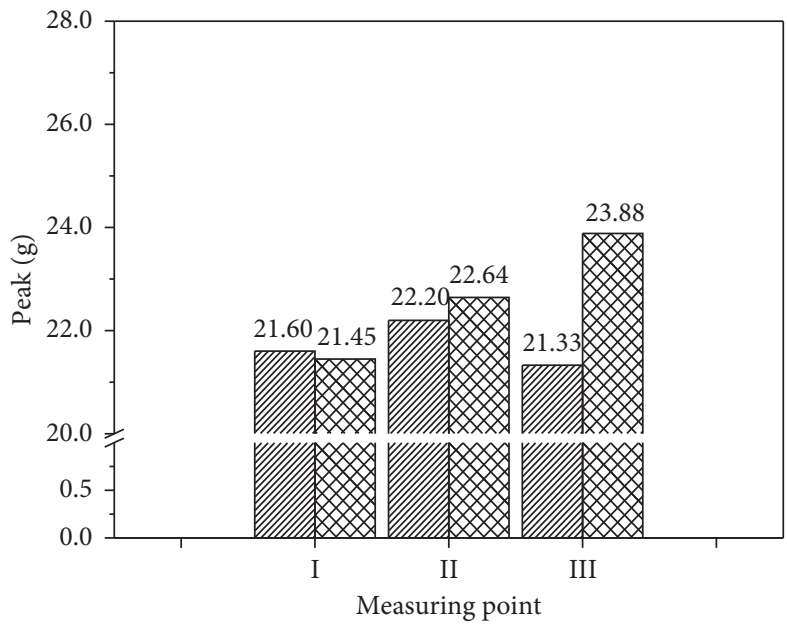

VIIIIA N-LVT

T-LVT

(a)

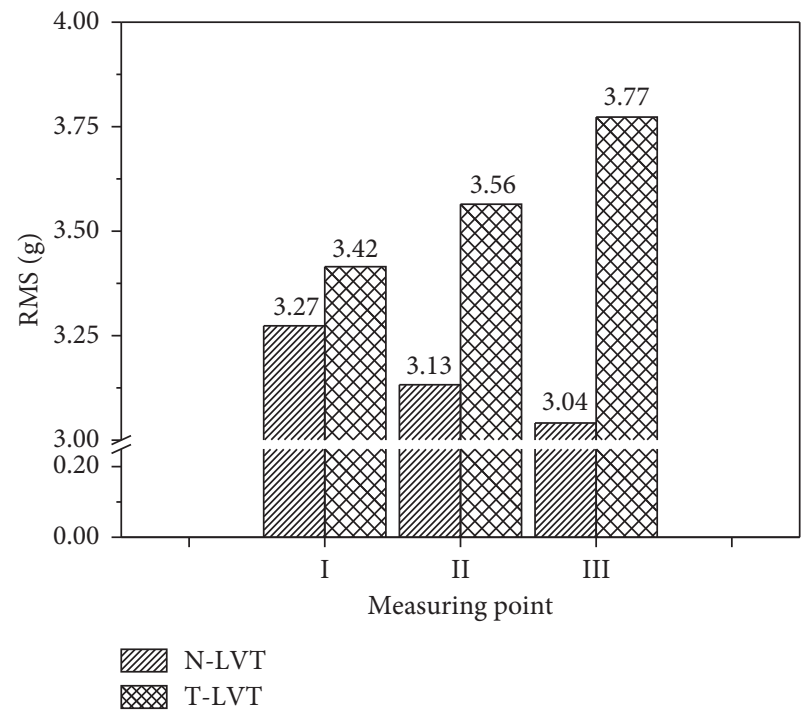

(b)

FIgURE 15: Bearing block acceleration peak and RMS. (a) Acceleration peak. (b) Acceleration RMS.

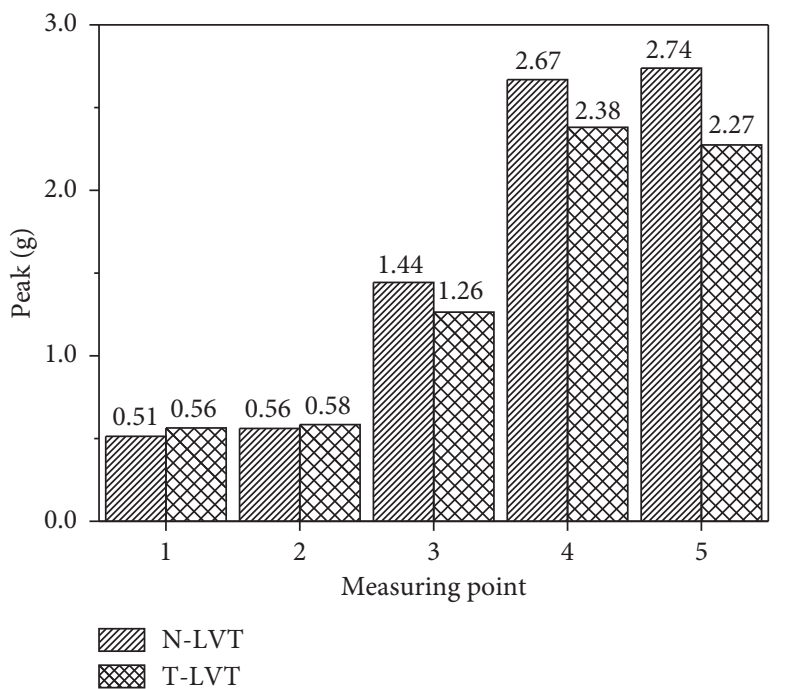

(a)

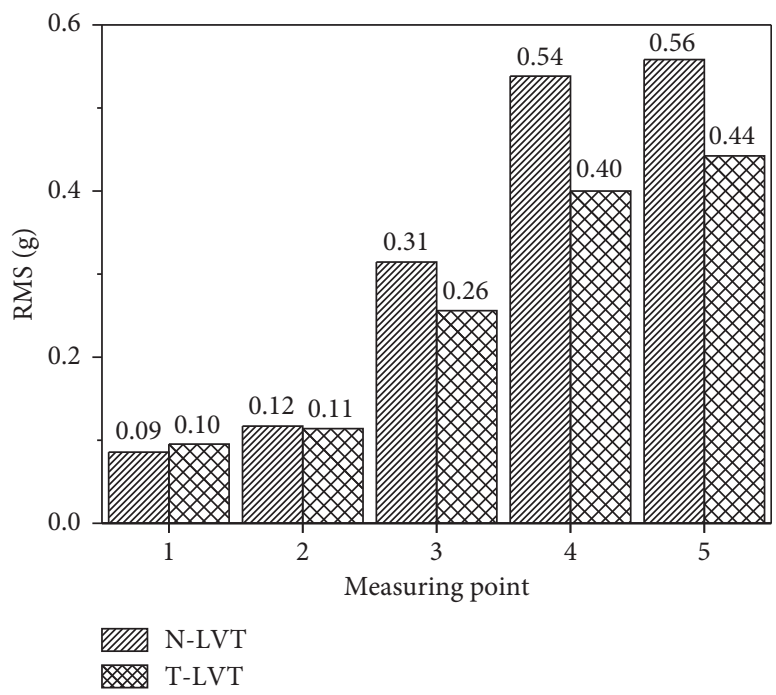

(b)

FIgUre 16: Track slab acceleration peak and RMS. (a) Acceleration peak. (b) Acceleration RMS.

It can be seen from Figures 15(a) and 15(b) that the acceleration distributions of the two LVTs bearing blocks surface are different. The acceleration peak and RMS of the $\mathrm{N}$-LVT are smaller than that of the T-LVT, and the reduction values are $2.55 \mathrm{~g}$ and $0.73 \mathrm{~g}$, respectively. Hence, the N-LVT is more effective. The maximum RMS of the T-LVT appears at the measuring point $\mathrm{I}$, which is in turn decremented to the measuring point III, and the N-LVT is successively 


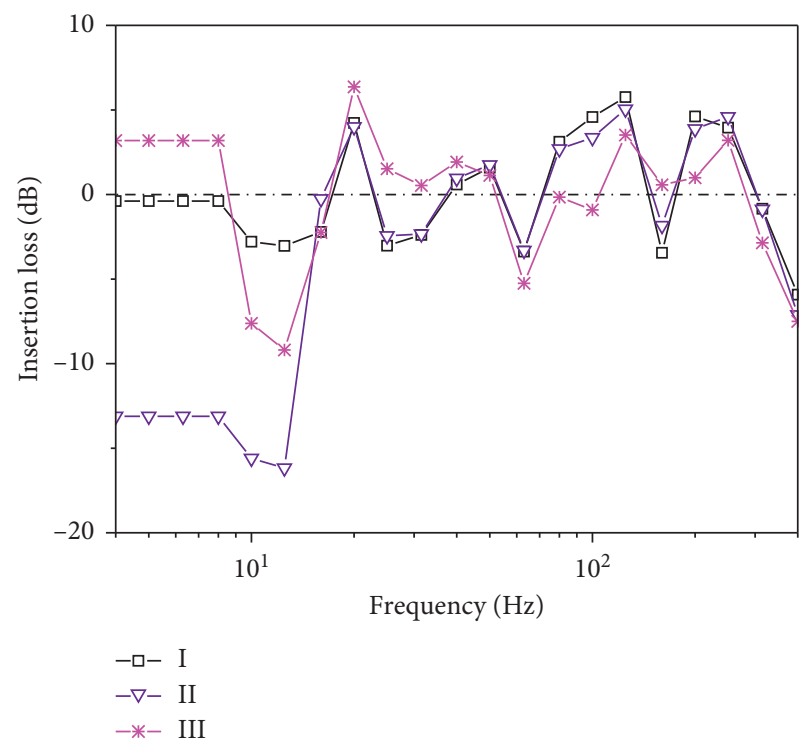

(a)

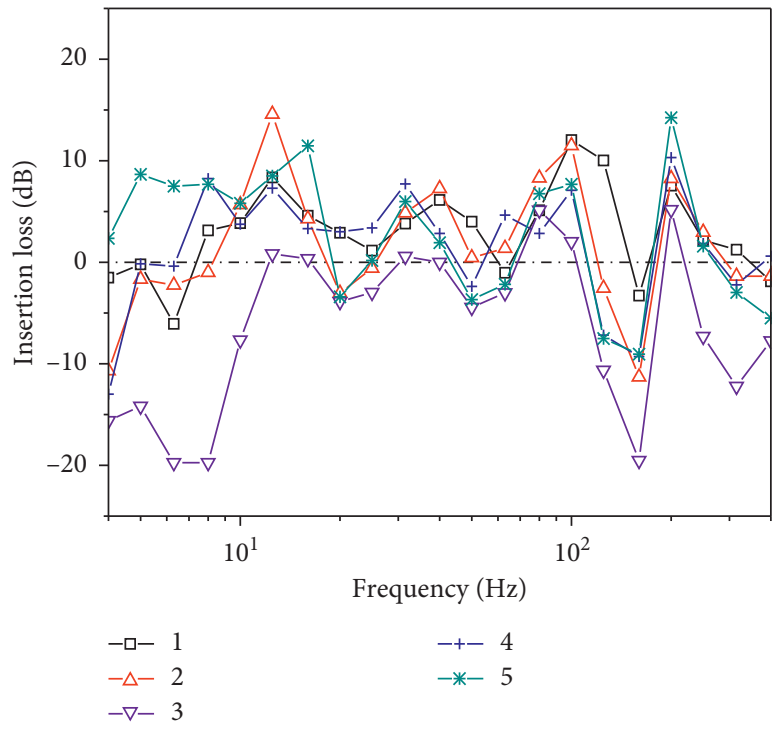

(b)

FiguRE 17: Insertion loss in different frequency: (a) bearing block; (b) track slab.

decreased from the measuring point III to I, indicating that the vibration energy of the N-LVT bearing block surface near the center line of the track is higher. The situation is the opposite for the T-LVT. Since the N-LVT has a short side slope, the vibration acceleration is more evenly distributed on the surface of the bearing block.

It can be seen from Figures 16(a) and 16(b) that when the impact vibration is transmitted laterally to the midline at the surface of the track slab, vibrations of the two LVTs are weakened at the center line of the track slab, and the attenuation amplitude and the vibration level are nearly the same. When the edge of the track slab is transmitted laterally, the vibration levels increase, with the growth trend of the N-LVT being more obvious than that of the T-LVT. The peak and RMS of N-LVT at the edge of the track slab are $0.47 \mathrm{~g}$ and $0.22 \mathrm{~g}$ higher than that of the T-LVT, respectively. The surface acceleration attenuation of the integrated bearing block indicates that the N-LVT will not significantly increase the surface acceleration of the track slab while reducing the vibration level of the bearing block.

\subsection{Frequency-Domain Analysis of the Law of Lateral} Transmission along the Track. The insertion loss curve of the surface of the bearing block and the track slab is shown in Figures 17(a) and 17(b).

It can be concluded from Figure 17(a) that vibration changes around the surface of the bearing block are basically the same. The N-LVT has good vibration damping effect in the high-frequency range above $16 \mathrm{~Hz}$, especially at $80-$ $125 \mathrm{~Hz}$ and $200-250 \mathrm{~Hz}$. the T-LVT vibration is slightly lower in the center of bearing block below $16 \mathrm{~Hz}$. As shown in Figure 17(b), the vibration of the N-LVT track slab beneath the rail is higher than the N-LVT but has good vibration damping effect at other measuring points. As a result of the insertion loss of the track slab and the bearing block, it can be concluded that the N-LVT has a good vibration damping effect when the high-frequency vibration is transmitted to both sides of the track slab. The lowfrequency vibration state of the support block and the track slab beneath the rail is slightly disadvantageous.

\section{Conclusions}

This paper introduces the wheelset dropping impact experiment of two LVT full-scale structures to compare their vibration characteristics. Based on the results of timedomain-frequency-domain analysis, the transmission and attenuation laws of impact vibration along the longitudinal, vertical, and lateral directions of the track structure are investigated, and the dynamic performance of the two track structures is evaluated. The experiment results are analyzed and led to the following conclusions.

The time-domain results show that applying N-LVT can reduce the vibration acceleration peak by $3 \%, 9.5 \%$, and $11.1 \%$ at the rail and the bearing block of wheel-rail impact position, respectively. The first and total attenuation period are reduced by $37.0 \%$ and $21.3 \%$, respectively.

The frequency-domain results show that the N-LVT overall vibration levels are reduced by $1.5 \mathrm{~dB}, 1.5 \mathrm{~dB}$, $-1.6 \mathrm{~dB}, 6.0 \mathrm{~dB}$, and $7.1 \mathrm{~dB}$ at the rail, the bearing block, the track slab, the foundation base, and the ground, respectively.

The application of N-LVT acceleration amplitude longitudinal attenuation speed at the bearing block and the track slab along the longitudinal direction of the rail is slightly slower than the T-LVT, but this does not affect the operational safety of heavy-haul railway trains.

These results indicate that N-LVT does generate a positive effect on vibration mitigation. This is extremely obvious at the ground, which is beneficial for reducing the vibration level of the tunnel base and the lining structure. Analysis and verification of the advantages of the N-LVT in attenuating the vibration of the track structure can lay the 
foundation for further optimization and field application of the N-LVT based on the study.

\section{Data Availability}

The data used to support the findings of this study are included within the article.

\section{Conflicts of Interest}

The authors declare that they have no conflicts of interest.

\section{Acknowledgments}

This work was supported by the High-Speed Railway Joint Fund of National Natural Science Foundation of China (Grant U1734208), the Major Program of National Natural Science Foundation of China (Grant 11790283), and the Science and Technology Foundation of China Railway 14th Bureau Corporation Limited (Grant 20160016).

\section{References}

[1] Q. Wu, S. Luo, and C. Cole, "Longitudinal dynamics and energy analysis for heavy haul trains," Journal of Modern Transportation, vol. 22, no. 3, pp. 127-136, 2014.

[2] A. Wijeweera, H. To, and M. Charles, "An empirical analysis of Australian freight rail demand," Economic Analysis and Policy, vol. 44, no. 1, pp. 21-29, 2014.

[3] R. Pittman, "Risk-averse restructuring of freight railways in China," Utilities Policy, vol. 19, no. 3, pp. 123-124, 2011.

[4] J. Sadeghi, "Field Investigation on vibration behavior of railway track systems," International Journal of Civil Engineering, vol. 8, no. 3, pp. 232-241, 2010.

[5] J. Bian, Y. Gu, and M. H. Murray, "A dynamic wheel-rail impact analysis of railway track under wheel flat by finite element analysis," Vehicle System Dynamics, vol. 51, no. 6, pp. 784-797, 2013.

[6] C. G. Nicieza, M. I. Á. Fernández, A. M. Díaz, A. E. Á. Vigil, and F. A. Fernández, "Failure analysis of concrete sleepers in heavy haul railway tracks," Engineering Failure Analysis, vol. 15, no. 1-2, pp. 90-117, 2008.

[7] D. W. Barke and W. K. Chiu, "A review of the effects of outof-round wheels on track and vehicle components," Proceedings of the Institution of Mechanical Engineers, Part F: Journal of Rail and Rapid Transit, vol. 219, no. 3, pp. 151-175, 2006.

[8] S. G. Newton and R. A. Clark, "An investigation into the dynamic effects on the track of wheelflats on railway vehicles," Journal of Mechanical Engineering Science, vol. 21, no. 4, pp. 287-297, 2006.

[9] T. X. Wu and D. J. Thompson, "The effects of track nonlinearity on wheel/rail impact," Proceedings of the Institution of Mechanical Engineers, Part F: Journal of Rail and Rapid Transit, vol. 218, no. 1, pp. 1-15, 2006.

[10] R. V. Dukkipati and R. Dong, "Impact loads due to wheel flats and shells," Vehicle System Dynamics, vol. 31, no. 1, pp. 1-22, 1999.

[11] B. S. Werning, M. Beier, K. G. Degen, and D. Stiebel, "Research on noise and vibration reduction at DB to improve the environmental friendliness of railway traffic," Journal of Sound and Vibration, vol. 293, no. 3-5, pp. 1058-1069, 2006.
[12] H. P. Liu, T. X. Wu, and Z. G. Li, "Theoretical modelling and effectiveness study of rail vibration absorber for noise control," Journal of Sound and Vibration, vol. 323, no. 3-5, pp. 594-608, 2009.

[13] P. A. Costa, R. Calçada, and A. S. Cardoso, "Ballast mats for the reduction of railway traffic vibrations. Numerical study," Soil Dynamics and Earthquake Engineering, vol. 42, pp. 137150, 2012.

[14] M. F. M. Hussein and H. E. M. Hunt, "A numerical model for calculating vibration from a railway tunnel embedded in a full-space," Journal of Sound and Vibration, vol. 305, no. 3, pp. 401-431, 2007.

[15] L. Auersch, "Dynamic behavior of slab tracks on homogeneous and layered soils and the reduction of ground vibration by floating slab tracks," Journal of Engineering Mechanics, vol. 138, no. 8, pp. 923-933, 2012.

[16] J. Wang and X. Zeng, "Numerical simulations of vibration attenuation of high-speed train foundations with varied trackbed underlayment materials," Modal Analysis, vol. 10, no. 8, pp. 1123-1136, 2016.

[17] S. Kaewunruen and A. M. Remennikov, "Dynamic crack propagations in prestressed concrete sleepers in railway track systems subjected to severe impact loads," Journal of Structural Engineering, vol. 136, no. 6, pp. 749-754, 2010.

[18] W. M. Zhai, K. Y. Wang, and J. H. Lin, "Modelling and experiment of railway ballast vibrations," Journal of Sound and Vibration, vol. 270, no. 4-5, pp. 673-683, 2004.

[19] W. Ferdous and A. Manalo, "Failures of mainline railway sleepers and suggested remedies-review of current practice," Engineering Failure Analysis, vol. 44, pp. 17-35, 2014.

[20] F. Rezaie, M. R. Shiri, and S. M. Farnam, "Experimental and numerical studies of longitudinal crack control for prestressed concrete sleepers," Engineering Failure Analysis, vol. 26, pp. 21-30, 2012.

[21] C. Esveld, Recent Developments in Slab Track application, Delft University of Technology, Delft, Netherlands, 1999.

[22] P.-E. Gautier, "Slab track: review of existing systems and optimization potentials including very high speed," Construction and Building Materials, vol. 92, no. 1, pp. 9-15, 2015.

[23] M. li and R. Niu, "Ballastless track design of test section of Shanxi Center-south Railway," Railway Standard Design, vol. 60, no. 9, pp. 1-3, 2016, in Chinese.

[24] C. Zhao and P. Wang, "Experimental study on the vibration damping performance of rubber absorbers for ballastless tracks on viaduct," China Railway Science, vol. 34, no. 4, pp. 8-13, 2013.

[25] J.-Y. Zhu, "Analysis of dynamic behaviour of low vibration track under wheel load drop by a finite element method algorithm," Proceedings of the Institution of Mechanical Engineers, Part F: Journal of Rail and Rapid Transit, vol. 222, no. 2, pp. 217-223, 2008.

[26] X. P. Cai, D. C. Li, Y. R. Zhang, Q. Miao, and R. X. Cui, "Experimental study on the vibration control effect of long elastic sleeper track in subways," Shock and Vibration, vol. 2018, Article ID 6209518, 13 pages, 2018.

[27] S. Yoshihiko, T. Morimura, and S. Watanabe, "Theoretical analyses and experimental results on track moduli with use of wheel-set drop test," Vehicle System Dynamics, vol. 24, no. 1, pp. 164-179, 2007.

[28] S. Yoshihiko, New Track Mechanics, Shudao Society, Tokyo, China, 5th edition, 1997.

[29] Y. X. Zhong and B. Xu, "Experiment on wheel-rail vertical forces with use of wheel-set drop," Journal of Railway Engineering Society, vol. 1, pp. 182-194, 1986, in Chinese. 
[30] ISO 2631-1, Mechanical Vibration and Shock-Evaluation of Human Exposure to Whole-Body Vibration-Part 1-General Requirements, ISO, Geneva, Switzerland, 1997.

[31] Standardization Administration of China, GB/T 13441-2007, Measurement Method of Environmental Vibration of Urban Area Body Vibration-Part 1-General Requirements, Standardization Administration of China, Beijing, China, 2007. 


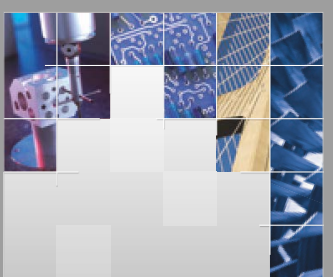

\section{Enfincering}
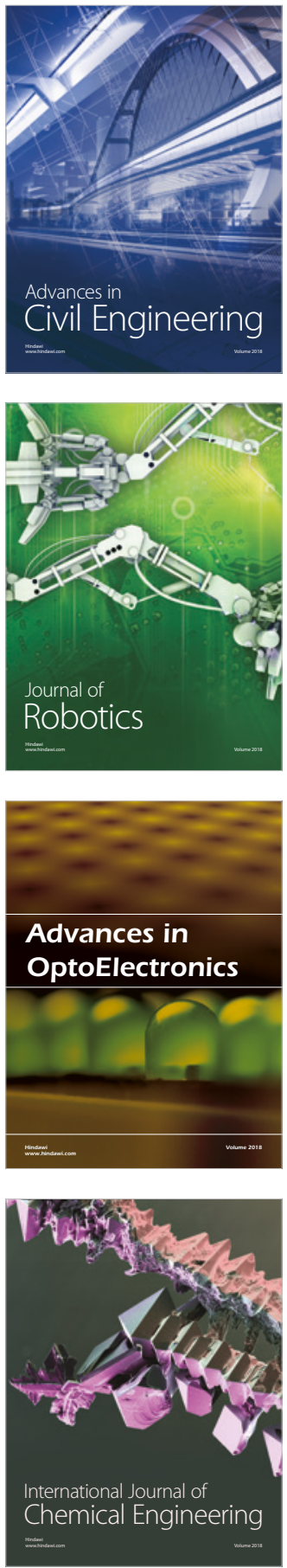

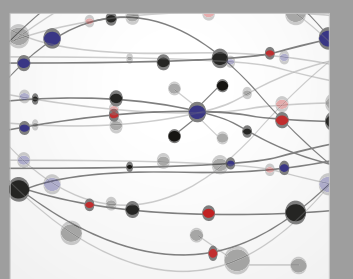

\section{Rotating \\ Machinery}

The Scientific World Journal

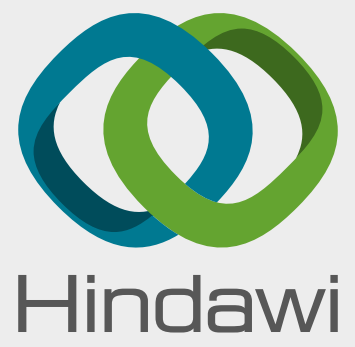

Submit your manuscripts at

www.hindawi.com
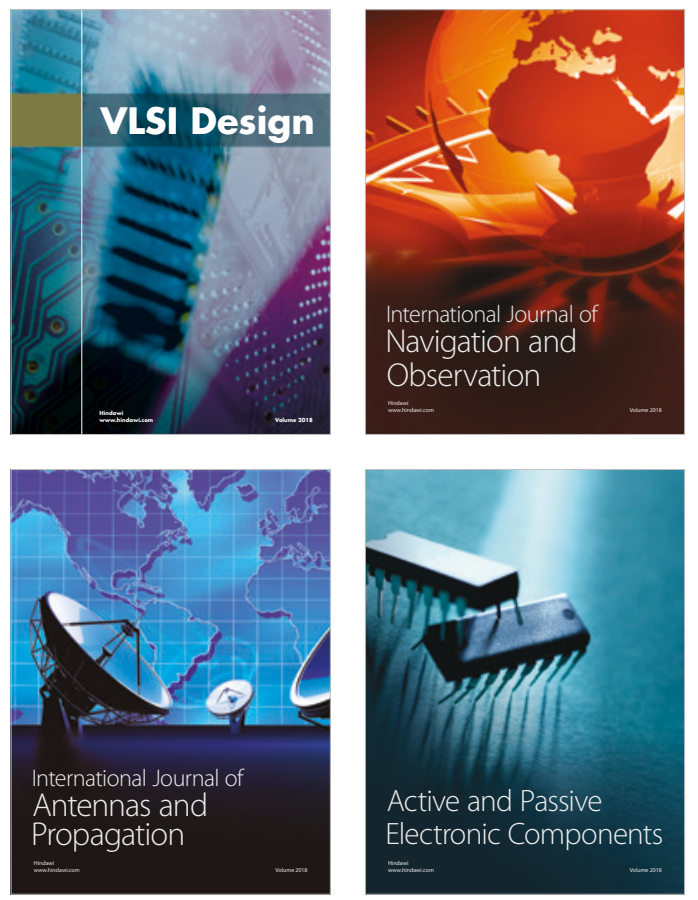
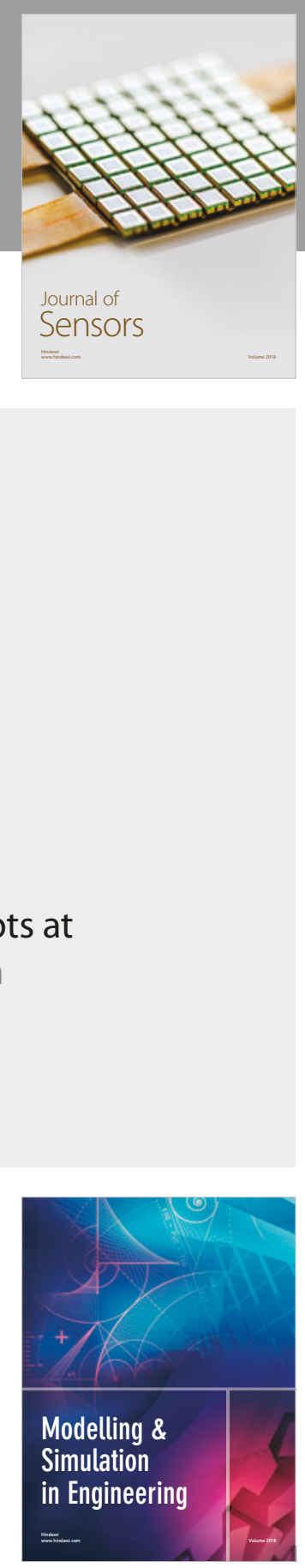

\section{Advances \\ Multimedia}
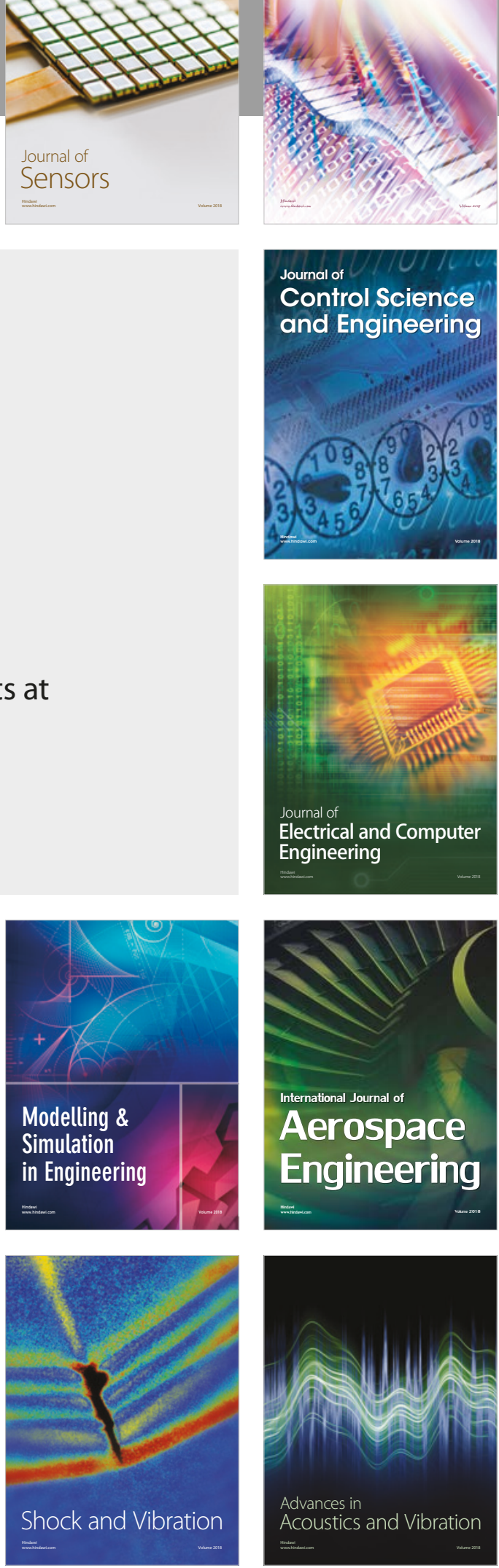